Hui, C., Gardner, L. and Nethercot, D. A. (2016). Moment redistribution in cold-formed steel continuous beams. Thin-Walled Structures. 98, 465-477.

\title{
Moment redistribution in cold-formed steel continuous beams
}

\author{
Chi Hui ${ }^{\text {a }}$, Leroy Gardner ${ }^{\text {a }}$, David A Nethercot ${ }^{\text {a }}$ \\ ${ }^{a}$ Imperial College London, Dept. of Civil and Environmental Engineering, London, UK
}

\begin{abstract}
The external envelope of steel framed industrial buildings normally involves the use of purlins and rails spanning between the main hot-rolled frames to support the roofing/cladding. These purlins are typically light-gauge cold-formed steel members of complex shape for which the thin-walled nature of the material means that local instabilities will significantly influence their structural behaviour. Economic design should be based on failure of the system, recognising the opportunity for redistribution of moments. This paper presents the findings from a numerical investigation of the degree of moment redistribution in continuous cold-formed steel beams subjected to a downward (gravity) uniformly distributed load (UDL). Three types of nonlinear finite element analysis were validated against previously reported physical tests: (i) continuous two-span beams subjected to a UDL, (ii) single span beams subjected to a central point load producing a moment gradient and (ii) single span beams subjected to two point loads producing a central region under pure bending. The interior support moments from the continuous beam models were compared against reference moment capacities from the three-point bending models. Based on various different section sizes, covering a range of cross-sectional slenderness, full moment redistribution with no drop-off in moment at the interior support was found to be possible only for stocky sections but not for slender sections. In the case of slender sections, local and distortional buckling caused a reduction in interior support moment prior to failure of the system. Hence a design formula is proposed to estimate the post-peak reduction of interior support moment from its initial peak, and this reduced moment capacity is then used in conjunction with the full span moment to determine the load-carrying capacity of the system. Comparisons show the proposed approach to offer accurate prediction of observed system failure loads.
\end{abstract}




\section{Introduction}

Modern light roof construction for industrial or warehouse buildings normally comprises cold-formed steel purlins covered with sheeting. These purlins are used as secondary steelwork between the main frames. The thin-walled nature of cold-formed steel members makes them susceptible to cross-sectional instabilities such as local and distortional buckling. With buckling limiting the overall load carrying capacity, the basic assumption for the application of plastic design that the first hinge to form in a dual span system can maintain its moment capacity until a collapse mechanism is formed, is not always guaranteed. This paper reports on a study designed to provide suitable modifications to permit the basic concept of plastic theory to be applied in such cases.

Many research projects have been carried out to investigate the structural behaviour of multispan purlin systems. Willis and Wallace [1] and Hancock et al. [2] conducted tests on purlin systems with through-fastened roof panels, while previous researchers [3-5] conducted studies to investigate the flexural behaviour of lapped moment connections for single span and 2-span $\mathrm{Z}$ sections. As an alternative to conducting full scale testing which can be expensive and time consuming, finite element (FE) models have also been increasingly used for research into cold-formed steel. Early publications on FE modelling of cold-formed steel members appeared more than a decade ago [6]; since then treatments have become more robust and practical with the use of faster processing power. Recently, Haidarali and Nethercot [7-9] successfully analysed cold-formed Z sections using ABAQUS [10] and investigated the local/distortional buckling behaviour for a range of different $\mathrm{Z}$ section arrangements subjected to pure bending.

Research into the inelastic strength of cold-formed steel members is relatively limited. Reck et al. [11] and Yener and Peköz [12-14] have shown that the inelastic strength reserve for cold-formed steel beams due to partial plastification of the cross-section can permit increases of up to $35 \%$ beyond the yield moment for many practical shapes. While Eurocode 3 [15] recognises this potential inelastic strength and the scope for moment redistribution through appropriate physical testing, direct guidance on moment redistribution in multi-span coldformed steel systems is lacking. In the present study, FE models are first validated against available test data, and then utilised to generate a series of parametric results. These results are used to underpin a proposed design approach to allow for moment redistribution in 2-span continuous purlin systems. 


\section{Design Approach for 2-span systems}

For a statically indeterminate 2-span system, as shown in Fig.1, additional load carrying capacity can be achieved if the cross-section bending moment capacity can be maintained over sufficiently large rotations to allow for moment redistribution and exploitation of the unused moment capacity within the span. This principle is commonly employed when designing hot-rolled steelwork and has been adapted for reinforced concrete and composite construction. To date, moment redistribution is rarely considered in cold-formed steel design since most sections comprise of plates with high width-to-thickness ratios that typically exceed the limits outlined for plastic design. Hence, 2-span purlin systems are generally designed based on elastic principles, which only utilise the full cross-sectional moment capacity at the central support but not within the span. However, due to the statically indeterminate nature of the 2-span system, there is the potential to use a greater proportion (possibly all) of the unused moment capacity within the span by allowing for redistribution of moments.

\subsection{Moment redistribution}

Given the ideal situation of full plastic redistribution of moments, the bending moment at the interior support, $\mathrm{M}_{\text {support }}$ and within the span, $\mathrm{M}_{\text {span }}$ both reach their full cross-sectional capacities because the moment-rotation relationship for the support region is such that no significant drop off in capacity occurs before rotations develop sufficiently to allow the span moment to reach its capacity. For such cases, it is common for the designer to adopt an idealised elastic-perfectly plastic moment-rotation relationship, as demonstrated in Fig. 2, where $\mathrm{M}_{\mathrm{p}}$ is the plastic moment capacity and $\theta_{\mathrm{p}}$ is the rotation at $\mathrm{M}_{\mathrm{p}}$.

However, due to the high width-to-thickness ratios of the constituent elements, cold-formed steel purlins are susceptible to local instabilities such as local and/or distortional buckling. Thus the design issue for cold-formed steel construction is that the moment-rotation behaviour may differ from the ideal arrangement detailed in Fig. 2. Should this be the case, i.e. attaining full capacity within the span is accompanied by a reduction in interior support moment, then appropriate allowance must be made. 
To study the level of moment redistribution in indeterminate purlin systems, a series of 2span continuous and representative single span beams was modelled using ABAQUS [10]. For each 2-span FE model, two further single span models were created to generate reference values for the interior support and span moments in the 2-span model respectively. The largest sagging moment (elastically located at $0.375 \mathrm{~L}$ (see Fig. 3) from the beam ends) $\mathrm{M}_{\text {span }}$ in the 2-span system was represented by a single span model subjected to 4-point bending (i.e. uniform bending between point loads) $\mathrm{M}_{1}$. Knowing that the moment-rotation response at the interior support is influenced by the interaction of a sharp moment gradient and a high shear force and concentrated load, the interior support $M_{\text {support }}$ was represented by the maximum moment obtained from a single span model of the same cross-section subjected to 3-point bending $\mathrm{M}_{3}$ with length L' and with the load introduced in the same manner as in the corresponding continuous beam such that the effect of the concentrated force is captured, as shown in Fig. 3. The length L' is the length of the hogging region from the 2-span model. For the 4-point bending models used to determine $\mathrm{M}_{1}$, the span length $\mathrm{L}^{*}$ was kept constant at $4880 \mathrm{~mm}$, which was sufficient for local and distortional buckling to freely develop within the constant moment region. $\mathrm{M}_{1}$ and $\mathrm{M}_{3}$ are then considered as reference bending moments for the span and interior support regions respectively, that can capture the local and/or distortional buckling response of the cross-sections and, in the case of the $\mathrm{M}_{3}$ models, can allow for the influence of moment gradient, shear force and concentrated load, the latter of which will be a function of the cleat arrangement used to secure the purlins.

The ultimate load carrying capacity qult for a 2-span system with equal spans subjected to a UDL can be determined, from equilibrium, by solving for q in Eq. 1, providing the values of interior support moment $\mathrm{M}_{\text {support }}$ and span moment $\mathrm{M}_{\text {span }}$ at qult are known.

$$
\mathrm{M}_{\text {span }}=\frac{\left(\mathrm{qL}^{2}+2 \mathrm{M}_{\text {support }}\right)^{2}}{8 \mathrm{qL}^{2}}
$$

\section{3. $\quad$ Finite element model}

Nonlinear static analyses of the cold-formed steel sections were performed using the modified Riks method by adopting the "*STATIC, RIKS" command in ABAQUS. Material and geometrical nonlinearities were incorporated in the FE models through the *PLASTIC 
and *STEP, NLGEOM commands respectively. The key features of the models are described in the following sub-sections, while validation of the model and parametric studies are represented in Sections 4 and 5, respectively.

\subsection{Material modelling}

Unlike hot-rolled steel sections, the stress-strain characteristics for cold-formed steel members exhibit a more gradual and rounded yielding response. Based on the sensitivity study results in [7], the two-stage modified Ramberg-Osgood engineering stress-strain expressions proposed by Gardner and Ashraf [16], as given by Eq. 2 and 3, were chosen to replicate the stress-strain response of cold-formed steel throughout this paper. The material model consists of two different expressions: the modified Ramberg-Osgood expression $[17,18]$ for stresses up to the $0.2 \%$ proof stress $\sigma_{0.2}$, and a second curve from $\sigma_{0.2}$, passing through the $1.0 \%$ proof stress $\sigma_{1.0}$ and up to the ultimate tensile stress $\sigma_{u}$. The $0.2 \%$ proof stress acts as a new origin for the second stage of the modified Ramberg-Osgood formula, and ensures that continuity is maintained at the transition point between the two expressions.

$$
\begin{array}{ll}
\varepsilon=\frac{\sigma}{\mathrm{E}}+0.002\left(\frac{\sigma}{\sigma_{0.2}}\right)^{\mathrm{n}} & \text { for } \sigma \leq \sigma_{0.2} \\
\varepsilon=\frac{\sigma-\sigma_{0.2}}{\mathrm{E}_{0.2}}+\left(\varepsilon_{1.0}-\varepsilon_{0.2}-\frac{\sigma_{1.0}-\sigma_{0.2}}{\mathrm{E}_{0.2}}\right)\left(\frac{\sigma-\sigma_{0.2}}{\sigma_{1.0}-\sigma_{0.2}}\right)^{\mathrm{n}_{0.21 .0}^{\prime}}+\varepsilon_{0.2} & \text { for } \sigma_{0.2}<\sigma \leq \sigma_{\mathrm{u}}
\end{array}
$$

where $\sigma$ and $\varepsilon$ are the engineering stress and strain respectively, E is the Young's modulus of the material, $\varepsilon_{0.2}$ and $\varepsilon_{1.0}$ are the total strain at the $0.2 \%$ and $1.0 \%$ proof stresses and $\mathrm{n}$ and $\mathrm{n}_{0.2,1.0}$ influence the degree of roundness of the stress-strain curve. $\mathrm{E}_{0.2}$ is the tangent modulus at the $0.2 \%$ proof stress. Initially proposed by Haidarali and Nethercot [7], the values of $\sigma_{1.0}$ for the present study were estimated using Eq. 4.

$$
\frac{\sigma_{1.0}}{\sigma_{0.2}}=1.876 \sigma_{0.2}^{-0.095}
$$

in which $\sigma_{0.2}$ is in $\mathrm{N} / \mathrm{mm}^{2}$. Based on tensile coupon tests results by Hui [19], yield and ultimate strength enhancements in the corner regions of the modelled cold-formed sections were incorporated into the FE models by applying the strength increases given by Eq. 5 and 6. 


$$
\begin{array}{ll}
\sigma_{0.2, \text { corner }}=1.05 \sigma_{0.2} & \text { for } 0^{\circ}<\theta<90^{\circ} \\
\sigma_{0.2, \text { corner }}=1.10 \sigma_{0.2} & \text { for } 90^{\circ} \leq \theta<180
\end{array}
$$

where $\sigma_{0.2, \text { corner }}$ is the estimated $0.2 \%$ proof strength in the corner regions, $\theta$ is the internal angle of any corner and $\sigma_{0.2}$ is the $0.2 \%$ proof strength of the flat material.

\subsection{Modelling the restraining effects of cladding}

A two-spring model was used to replicate the restraining behaviour of the type of profiled sheeting attached to the top flange of cold-formed purlins - see Fig. 4. The restraining behaviour acting on the beam offered by each fastener was modelled using 'SPRINGA' 3D linear translational spring elements. The spring vertically restrains the connected top flange and acts in both compression (bearing into sheeting) and tension (fastener pull-out). Haidarali and Nethercot [7] found that the precise value of spring stiffness selected had little effect on the in-plane failure mode and section capacity, provided the spring stiffness was greater than a threshold stiffness value. The threshold value determines whether section failure is triggered by local buckling (high stiffness) or distortional buckling (low stiffness). Even though the true threshold value will be a function of cross-section geometry, the linear spring stiffness was set to $5000 \mathrm{~N} / \mathrm{mm}$ for both tension and compression.

Compression-only springs were also attached to the lip/flange junction between fastener locations to prevent any negative vertical displacement. These springs were modelled using 'SPRINGA' elements and assigned nonlinear stiffness values using the *SPRING, NONLINEAR command in ABAQUS [10]. This set of nonlinear springs prevents the flange deforming upwards (into the sheeting) whilst leaving it free to deform downwards. The spring stiffness was again set to $5000 \mathrm{~N} / \mathrm{mm}$, when operating in compression, but with negligible tensile stiffness. For both types of springs, the command *EQUATION was used for each slave spring node to ensure the spring always remained directly above the connected beam node, as shown in Fig. 4. The translational and longitudinal displacements (DOF 1 and 3) of the beam node were equated to the slave spring node. The vertical displacement (DOF

2) at the web/flange junction was equated to the slave spring node to prevent additional extension of the spring due to global bending deformations. 


\subsection{Geometrical imperfections}

Geometric imperfections were generated by directly specifying deformed geometry in the FE models. The method of creating the initial imperfections was carried out in two stages: (i) determine elastic local and distortional buckling mode shapes using the finite strip program CUFSM [20] based on the section dimensions employed in the ABAQUS FE models, and (ii) distribute the mode shapes longitudinally along the member lengths using sinusoidal functions and adopting the half-wavelength of the elastic buckling modes, and with the amplitudes of $0.3 \mathrm{t}$ and $0.1 \mathrm{t}$ for distortional and local buckling respectively as proposed by Hui [19]. In all cases, an odd number of half-wavelengths was specified along the member length, and the sign of the function was such that imperfections were inwards (i.e. towards the neutral axis) at mid-length. This shape was generally found to be the most severe in terms of achieved load-carrying capacity [19,21].

\subsection{Loading/boundary conditions}

Models were created of cold-formed steel sections in single-span 3-point and 4-point bending configurations and 2-span continuous arrangements under uniformly distributed loading. The adopted loading and boundary conditions are described in this sub-section. The modelled beams were fitted with flat and corner plates at points of concentrated loading and support to replicate the localised restraining effect from loading plates and cleats. The flat and corner plates were modelled using S4R elements and assigned thicknesses of $6 \mathrm{~mm}$ and $3 \mathrm{~mm}$, respectively with an artificially high elastic modulus equal to ten times that of steel. The connecting bolts between loading plates and the beam were assumed to be 'perfect' with no bolt slip and were simulated using the *TIE command between the nodes located on the flat plate and the beam. This ensures that all 6 degrees of freedom (DOF) from the beam and plate at the tie locations are equated. Lateral restraints along the beam at the web/flange junction were applied in the FE model by adding out-of-plane translational (DOF1) boundary conditions. To prevent rigid body motion longitudinal translational boundary conditions (DOF3) were applied at the midspan web nodes. Simple end supports were modelled by fixing DOFs 1, 2, 5 and 6 at the bottom flange nodes. For the single span tests, the load was applied through the centre of the flat stiff plates using the ABAQUS command *CLOAD. A typical 3-point bending FE model is shown in Fig. 5. 
The uniformly distributed load (UDL) for the 2-span tests was modelled using a pressure load by applying the load through the smaller flat portion of the top flange using *DLOAD, as shown in Fig. 6. In order to reduce the model size and computational cost, only one half of the continuous 2-span beams was modelled by applying appropriate boundary conditions. *BOUNDARY, ZSYMM (DOFs 3, 4 and 5=0) was applied at the interior support to ensure longitudinal symmetry.

\section{FE model validation}

The developed FE models were validated against the results of a range of single and 2-span physical tests [22-30], covering 4 section types: lipped Zeds, lipped channels, Zeta I sections and Zeta II sections, as shown in Fig. 7. Tests [22-30] were chosen as part of the model validation because each source fully reported the test setup geometry, measured geometrical dimensions, load-displacement responses, description of the failure modes, measured $0.2 \%$ proof stresses and for [22], measured geometrical imperfections. Wang and Zhang [22] conducted single span pure bending and moment gradient tests on various cold-formed shapes including lipped channel sections. Between 1979 and 1992, the University of Salford [24-30] carried out a series of studies comprising of three types of test on various Zeta sections: (i) single span tests subjected to a moment gradient (ii) 2-span gravity continuous beam tests under a UDL and (iii) 2-span uplift continuous beam tests under a UDL. Yu and Schafer [23] carried out a large number of pure (4-point) bending tests on both lipped channel and lipped zed sections. Distortional and lateral-torsional buckling was effectively restricted by suitably located bracing. A total of 61 comparisons between the FE models and physical tests were made. Table 1 presents a comparison between the ultimate capacities predicted by the developed FE models $\mathrm{q}_{\mathrm{FE}}$ and those achieved in the tests $\mathrm{q}_{\mathrm{test}}$, with a mean $\mathrm{q}_{\mathrm{FE}} / \mathrm{q}_{\text {test }}$ ratio of 1.004 and a coefficient of variation (COV) of 0.041 . The load-displacement responses from the FE models were in close agreement to those obtained from the tests, as shown in Figs. 8 and 9. The FE failure modes also correlated well with the observed failure modes. For a typical 2-span gravity FE model, distortional buckling of the compression (bottom) flange was observed first at the interior support, and final failure of the system was governed by local/distortional buckling in the span region at the compression (top) flange, as shown in Fig. 10. 


\section{Parametric study and design proposals}

The validated FE model is used in this section to investigate the behaviour of cold-formed steel sections in 2-span arrangements and to generate parametric data to underpin a proposed design method.

\subsection{Influence of section slenderness}

Fig. 11 shows a schematic bending moment diagram illustrating the typical behaviour of a stocky cross-section in a 2-span arrangement. Due to the prolonged moment-rotation response at the support region (approximated by a 3-point bending model $\mathrm{M}_{3}$ as shown in Fig. 12), the 2-span system behaviour accords closely with the ideal situation given by plastic theory, achieving full moment redistribution with no drop-off in moment at the interior support at the ultimate load of the system. Fig. 13 shows the $\mathbf{M}_{\text {span, }}, M_{\text {support }}$ and applied load $q$ responses plotted against the maximum vertical displacement. In this instance, the support moment $\mathrm{M}_{\text {support }}$ reaches the moment capacity achieved in a 3-point bending model $\mathrm{M}_{3}$, while the span moment is approximately equal to the moment capacity derived for uniform bending $M_{1}$. Figures 14, 15 and 16 show comparisons between typical deformed stress profiles for a 2-span purlin system (Fig. 14), together with the corresponding single span $M_{1}$ (Fig. 15) and $\mathrm{M}_{3}$ (Fig. 16) arrangements. For the chosen example, at the interior support, where negative bending, shear and the influence of concentrated force are at their highest, the distortional buckling of the compression flange and corresponding stress profiles from the 2-span model and the $\mathrm{M}_{3}$ model are in good agreement. Similar failure modes are also observed in span region in the 2-span model and the corresponding $\mathrm{M}_{1}$ model, with both showing significant plastification of the section, together with distortional buckling of the top flange.

However, for 2-span arrangements with slender cross-sections, the moment redistribution response is more akin to that of Fig. 17, with the interior support moment dropping below the $\mathrm{M}_{3}$ moment at the ultimate system load, due to the 'peaky' nature of the moment-rotation characteristics of slender cross-sections (Fig. 18). Fig. 19 shows the development of span and support moments in a typical 2-span system comprising slender cross-sections, in which the interior support moment reaches $\mathrm{M}_{3}$ but then drops away as the span moment $\mathrm{M}_{\text {span }}$ builds to its maximum value may be seen. The reduced $\mathrm{M}_{\text {support }}$ value corresponding to attaining the 
maximum $\mathrm{M}_{\text {span }}$ moment, which corresponds to the ultimate load-carrying capacity of the system is designated $\alpha \mathrm{M}_{3}$.

The above comparisons confirm the suitability of using the $\mathrm{M}_{1}$ and $\mathrm{M}_{3}$ models to represent the behaviour of the span and support regions of the 2-span system, though it should be emphasised, in the case of the $\mathrm{M}_{3}$ models, that the span length and the modelling of the means of load introduction should be consistent with the corresponding 2-span system to ensure that the influence of shear and concentrated load is accurately reflected. Furthermore, as addressed in the following sub-section, due account must be taken for the drop-off in moment at the interior support observed at the ultimate load of the system for slender crosssections.

\subsection{Alpha framework}

To investigate the degree of moment redistribution in continuous 2-span purlin arrangements subjected to gravity loading, a large range of sections, featuring the 35 Zeta I, Zeta II, Zed and channel sections listed in Table 2 were analysed using the validated FE models described in Section 4. For each cross-section, three 2-span models with 4, 6 and $8 \mathrm{~m}$ spans were analysed. For each 2-span FE model, two additional single span reference FE models were also simulated. In total, the study comprised $245 \mathrm{FE}$ analyses. The same FE modelling technique discussed in Section 3.1 was adopted as the basis for the FE models used for this parametric study. The geometric dimensions of the cross-sections examined in the parametric study are reported in Table 2 while the material properties were as follows: Young's modulus $\mathrm{E}=210,000 \mathrm{~N} / \mathrm{mm}^{2}, 0.2 \%$ proof stress $\sigma 0.2=390 \mathrm{~N} / \mathrm{mm}^{2}$ and fastener spacing (distance between the translational springs) $=250 \mathrm{~mm}$.

To quantify the drop-off in support moment for each 2-span model at ultimate load, the moment in the support region Msupport at the collapse load of the system was compared with the maximum moment $\mathrm{M}_{3}$ from the corresponding reference moment gradient FE model. A reduction factor for gravity loading, $\alpha_{\mathrm{FE}, \mathrm{g}}$ is defined as the ratio of $\mathrm{M}_{\text {support }}$ to $\mathrm{M}_{3}$ as shown in Eq. 7. $\alpha \mathrm{FE}, \mathrm{g}=1$ corresponds to full redistribution with no drop-off in support moment.

$$
\alpha_{\mathrm{FE}, \mathrm{g}}=\frac{\mathrm{M}_{\text {support }}}{\mathrm{M}_{3}} \quad 0 \leq \alpha_{\mathrm{FE}, \mathrm{g}} \leq 1
$$


The cross-section slenderness $\bar{\lambda}_{\mathrm{cs}}$ is defined as the square root of the ratio of the elastic yield moment $\mathrm{M}_{\mathrm{y}}$ to the elastic critical buckling moment $\mathrm{M}_{\mathrm{cr}}$ :

$\bar{\lambda}_{\mathrm{cs}}=\sqrt{\frac{\mathrm{M}_{\mathrm{y}}}{\mathrm{M}_{\mathrm{cr}}}}$

where $M_{c r}$ is the lesser of the elastic critical local buckling moment $M_{c r, l}$ or elastic critical distortional buckling moment $\mathrm{M}_{\mathrm{cr}, \mathrm{d}}$. The elastic buckling moment was obtained from CUFSM. Positive bending (top flange in compression) and negative bending (bottom flange in compression) were analysed using two separate cases to obtain the positive and negative cross-section slenderness values $\bar{\lambda}_{\mathrm{cs},+\mathrm{ve}}$ and $\bar{\lambda}_{\mathrm{cs},-\mathrm{ve}}$ respectively. As shown in Fig. 20, the $\alpha \mathrm{FE}, \mathrm{g}$ values for all cross-sections from the FE results are plotted against the negative cross-section slenderness $\bar{\lambda}_{\mathrm{cs},-\mathrm{ve}} . \bar{\lambda}_{\mathrm{cs},-\mathrm{ve}}$ was chosen because the cross-section at the interior support is subjected to a hogging moment where the bottom flange is in compression. The results were classified into their respective span/depth ratios ranging from L/d of 10 to 60. Fig. 20 shows that higher $\mathrm{L} / \mathrm{d}$ ratios tend to yield lower $\alpha_{\mathrm{FE}, \mathrm{g}}$ values than shorter spans for the same section.

\subsection{Design proposal}

Observing that the level of interior support moment reduction is influenced by both the crosssection slenderness and the span/depth ratio $(\mathrm{L} / \mathrm{d})$, a single design equation to predict the moment reduction factor $\alpha_{\text {design,g }}$ for all cross-sections, which is a function of both parameters, is proposed:

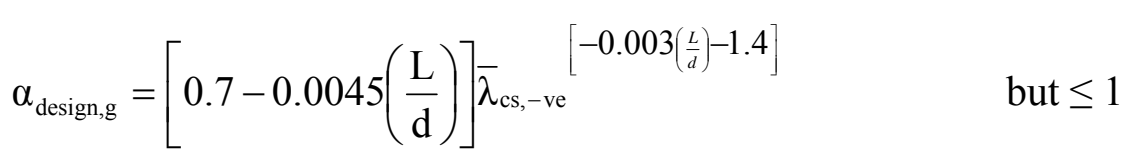

The ultimate loads q from the FE models were compared with capacity predictions from three design methods:

Method 1. Elastic design - Failure of the system is assumed to occur once the interior support moment reaches its peak $\mathrm{M}_{3}$ value.

Method 2. Plastic design - Assumes full plastic redistribution, with $\mathrm{M}_{3}$ at the interior support and $\mathrm{M}_{1}$ in the span. 
Method 3.

Proposed design method - makes allowance for redistribution, but also for the reduced interior support moment at ultimate load by utilising $\alpha_{\text {design,g }} \mathrm{M}_{3}$ at the interior support and $\mathrm{M}_{1}$ in the span.

The corresponding ultimate loads for each design method (1, 2 and 3) under gravity loading are defined as $\mathrm{q}_{1 \mathrm{~g}}, \mathrm{q}_{2 \mathrm{~g}}$ and $\mathrm{q}_{3 \mathrm{~g}}$ respectively. The bending moment values for $\mathrm{M}_{\text {span }}$ and $\mathrm{M}_{\text {support }}$ to use in Eq. 1 for each design method are summarised in Table 3. Comparisons between ultimate loads obtained from design methods 1, 2 and 3 and the 2-span FE results qFE,g for 4, 6 and $8 \mathrm{~m}$ spans are shown in Table 4 . Table 5 summarises the ultimate load comparisons for design methods 1, 2 and 3 for each cross-section shape, including the mean predicted/FE ratios and the coefficients of variation (COV). Designing the system based on elastic principles (design method 1) gave highly conservative results; the average $\mathrm{q}_{1, \mathrm{~g}} / \mathrm{q}_{\mathrm{FE}}$ for all cross-sections was 0.823 . The conservative results for all arrangements can be explained by the fact that all results showed additional load-carrying capacity once $\mathrm{M}_{\text {support }}$ reached its peak value. One case attained an additional 32\% more load beyond the time when $\mathrm{M}_{\text {support }}$ was at its maximum value. As expected, it is noted that as sections become more slender so the value of $M_{\text {support }}$ at the maximum system load falls further from its peak value. Thus the design calculation based on design method 2 overestimates capacity for these slender sections. Even though on average $\mathrm{q}_{2, \mathrm{~g}}$ is only $12 \%$ higher than $\mathrm{q}_{\mathrm{FE}, \mathrm{g}}$ (Table 4 ), the inclusion of stocky sections masks its poor ability to accurately predict the load-carrying capacity for slender sections. This is evident between cross-sectional shapes; the average design load overestimation for Zeta I sections was only 3\% because the sections were relatively stocky $\left(0.455<\bar{\lambda}_{\mathrm{cs},-\mathrm{ve}}<1.046\right)$, whereas for channel sections the average overprediction was much higher at $23 \%$ due to a larger number of slender sections $\left(0.866<\bar{\lambda}_{\text {cs,-ve }}<1.155\right)$. In general, design case 3 provides a robust method for calculating the 2-span collapse load for all 4 cross-section types and covering both slender and stocky sections. This is illustrated in Table 4.10 with a mean ratio of $\mathrm{q}_{3, \mathrm{~g}} / \mathrm{q}_{\mathrm{FE}, \mathrm{g}}$ equalling unity and low scatter $(\mathrm{COV}<0.050)$, with few results overpredicted and none by more than $9.4 \%$. Thus, the inclusion of the $\alpha_{\text {design,g }}$ factor as obtained from Eq. 9 permits the safe use of the plastic redistribution for the range of crosssections and span lengths covered.

The $\alpha$-framework can potentially be extended to alternative cold-formed steel cross-sections, means of load introduction (i.e. cleat type) and general arrangements. Even though only Zeta I, Zeta II, Zed and channel sections have been analysed in this study, it is expected that Eq. 9 
could still be applied to other cold-formed steel sections provided the cross-section slenderness is accurately determined and the influence of the specific cleat arrangement is adequately captured in the $\mathrm{M}_{3}$ models. The proposed method is also not strictly limited to moment input values obtained from FE analyses. The design procedure has the potential to be extended to cover a wider range of spans and support moment capacities obtained from various sources. A source of input moment values could include a mixture of physical testing, design calculations or numerical modelling.

\section{Conclusions}

The moment redistribution behaviour of continuous 2-span purlins subjected to gravity loading has been investigated herein by means of parametric studies using carefully validated FE models. A study consisting of 245 FE models for Zeta I, Zeta II, Zed and channel crosssections has been conducted for 4,6 and $8 \mathrm{~m}$ equal spans to evaluate the drop in moment from its peak moment capacity at the central support in two-span continuous beams upon reaching the collapse load of the system. The results from the study show how 2-span arrangements with slender cross-sections at large spans could lose up to $50 \%$ of their maximum support moment at the ultimate system load due to a sharp loss of moment at the interior support, whereas, for stocky cross-sections full moment redistribution, with no significant reduction in moment at the interior support at system failure can be achieved. A design formula is proposed to estimate the ultimate load-carrying capacity of 2-span purlin system by calculating a reduction value, $\alpha_{\text {design,g }}$ for the interior support moment at failure. The revised interior moment can be applied directly with the plastic mechanism approach of EC3. For the range of sections considered, a design approach assuming full redistribution with the full interior support moment (i.e. $\alpha_{\text {design, }}=1$ ) was found to be unconservative by $12 \%$ on average and by up to $60 \%$ for the more slender sections. Alternatively, the design approach based on elastic principles was found to be highly conservative by $17 \%$ on average. However, adopting the proposed design approach gives an average ratio of design load to FE results of $\mathrm{q}_{3, \mathrm{~g}} / \mathrm{q}_{\mathrm{FE}, \mathrm{g}}$ equal to unity and with a greatly reduced scatter.

\section{Acknowledgements}

The authors are very grateful to Ayrshire Metal Products for their financial and technical contributions to the project. 


\section{References}

[1] Willis CT, Wallace B. Behaviour of cold-formed steel purlins under gravity loading. Journal of Structural Engineering, ASCE. 1990; 116(8):2061-2069.

[2] Hancock GJ, Celeban M, Healy C, Georgiou PN, Ings NL. Tests of purlins with screw fastened sheeting under wind uplift. Proceedings of the Tenth International Specialty Conference on Cold-Formed Steel Structures. University of Missouri-Rolla, St Louis, MO. $1990 ; 393-419$.

[3] Ho HC, Chung KF. Experimental investigation into the structural behaviour of lapped connections between cold-formed steel Z sections. Thin-Walled Structures, 2004; 42(7):1013-1033.

[4] Dubina D, Ungureanu V. Behaviour of multi-span cold-formed Z-purlins with bolted lapped connections. Thin-Walled Structures, 2010; 48(5):866-871.

[5] Zhang L, Tong G. Moment resistance and flexural rigidity of lapped connections in multispan cold-formed Z purlin systems. Thin-Walled Structures, 2008; 46(5):551-560.

[6] Moreyra ME, Peköz T. Finite element studies on lipped channel flexural members. Proceedings of the Twelfth International Specialty Conference on Cold-Formed Steel Structures. University of Missouri-Rolla, St Louis, MO. 1994; 57-74.

[7] Haidarali MR, Nethercot DA. Finite element modelling of cold-formed steel beams under local buckling or combined local/distortional buckling. Thin-Walled Structures. 2011; 49(12):1554-1562.

[8] Haidarali MR, Nethercot DA. Local and distortional buckling of cold-formed steel beams with edge-stiffened flanges. Journal of Constructional Steel Research. 2011; 73:31-42.

[9] Haidarali MR, Nethercot DA. Local and distortional buckling of cold-formed steel beams with both edge and intermediate stiffeners in their compression flanges. Thin-Walled Structures. 2012; 54:106-112. 
[10] ABAQUS. Version 6.10. Pawtucket, USA: Hibbitt, Karlsson \& Sorensen, Inc. 2010.

[11] Reck HP, Peköz T, Winter, G. Inelastic strength of cold-formed steel beams. Journal of the Structural Division, ASCE. 1975; 101(ST11): 2193-2203.

[12] Yener M, Peköz T. Inelastic load carrying capacity of cold-formed steel beams. Proceedings of the Fifth International Specialty Conference on Cold-Formed Steel Structures. University of Missouri-Rolla, St Louis, MO. 1980; 145-174.

[13] Yener M, Peköz, T. Partial stress redistribution in cold-formed steel. Journal of Structural Engineering, ASCE. 1985; 111(6): 1169-1186.

[14] Yener M, Peköz, T. Partial moment redistribution in cold-formed steel. Journal of Structural Engineering, ASCE. 1985; 111(6):1187-1203.

[15] EN 1993-1-3. Eurocode 3: Design of Steel Structures - Part 1-3: General rules Supplementary Rules for Cold Formed Members and Sheeting. (CEN); 2006.

[16] Gardner L, Ashraf M. Structural design for non-linear metallic materials. Engineering Structures. 2006; 28(6): 926-934.

[17] Ramberg W, Osgood WR. Description of stress-strain curves by three parameters. Technical Note No. 902. National Advisory Committee for Aeronautics. Washington, D.C; 1943.

[18] Hill HN. Determination of stress-strain relations from the "offset" yield strength values. Technical note no. 927. National Advisory Committee for Aeronautics, Washington, D.C; 1944.

[19] Hui C. Moment redistribution in cold-formed steel purlin systems. PhD thesis. Imperial College London, UK. 2014.

[20] CUFSM Version 3.12, by Schafer, BW. Department of Civil Engineering, Johns Hopkins University; 2006. < http://www.ce.jhu.edu/bschafer/cufsm/ >.

[21] Borges Dinis P, Camotim D. Local/distortional model interaction in cold-formed steel lipped channel beams. Thin-Walled Structures. 2010; 48(10-11):771-785. 
[22] Wang H, and Zhang Y. Experimental and numerical investigation on cold-formed steel C-section flexural members. Journal of Constructional Steel Research. 2009; 65(5): 12251235 .

[23] Yu C, Schafer, BW. Local buckling tests on cold-formed steel beams. Journal of Structural Engineering, (ASCE). 2003; 129(12), 1596-1606.

[24] Bryan ER, Davies JM. Design basis of Zeta purlins: Part 1. Department of Civil Engineering Report. Ref. no. 80/132, University of Salford. 1979.

[25] Bryan, ER, Davies JM. Design basis of Zeta purlins: Part 2. Department of Civil Engineering Report. Ref. no. 80/135. University of Salford. 1980.

[26] Bryan ER, Deakin WH. Tests and design of $175 \mathrm{~mm}$ deep continuous and sleeved Zeta purlins. Department of Civil Engineering Report. Ref. no. J287. University of Salford. 1989.

[27] Deakin WH. Tests and design of $150 \mathrm{~mm}$ deep continuous and sleeved Zeta purlins rolled from Z35 material. Department of Civil Engineering Report. Ref. no. SJ450. University of Salford. 1991.

[28] Deakin, WH. Tests and design of $200 \mathrm{~mm}$ deep x $1.4 \mathrm{~mm}$ thick continuous and sleeved Zeta purlins. Department of Civil Engineering Report. Ref. no. SJ457. University of Salford. 1991

[29] Davies JM, Deakin WH. Sleeve tests on Zeta II purlins. Department of Civil Engineering Report. Ref. no. SJ498. University of Salford. 1992.

[30] Deakin WH, Bryan ER, Davies, JM. Bending tests on prototype purlins. Department of Civil Engineering Report. Ref. no. 79/120. University of Salford. 1979. 
q

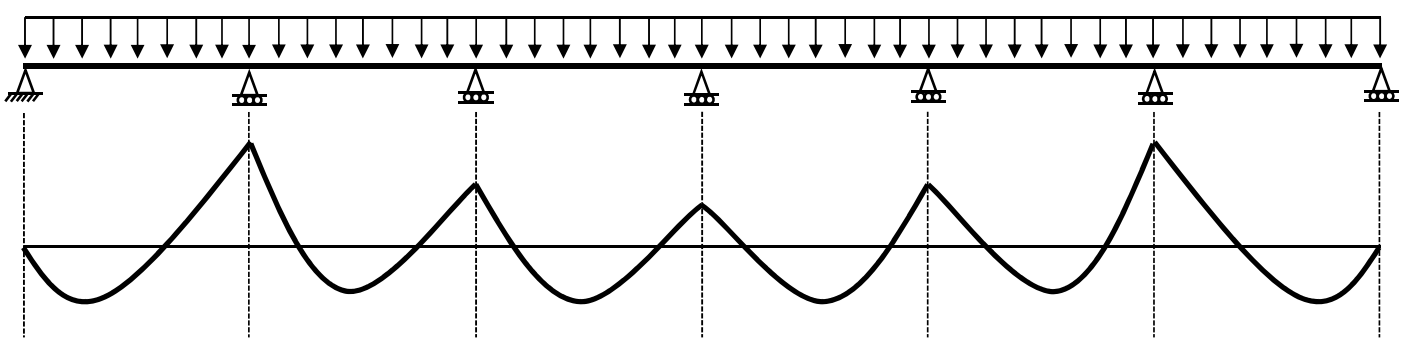

(a)

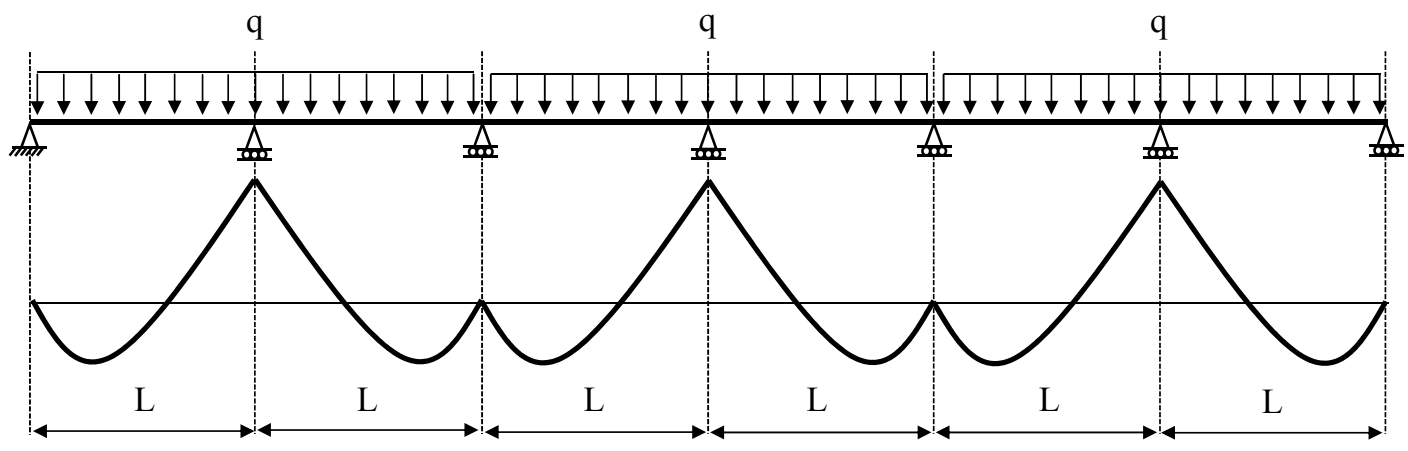

Fig.1. Elastic bending moment diagram (BMD) for (a) multi-span and (b) a series of 2-span purlin systems

$$
M_{\text {support }}=M_{p}
$$
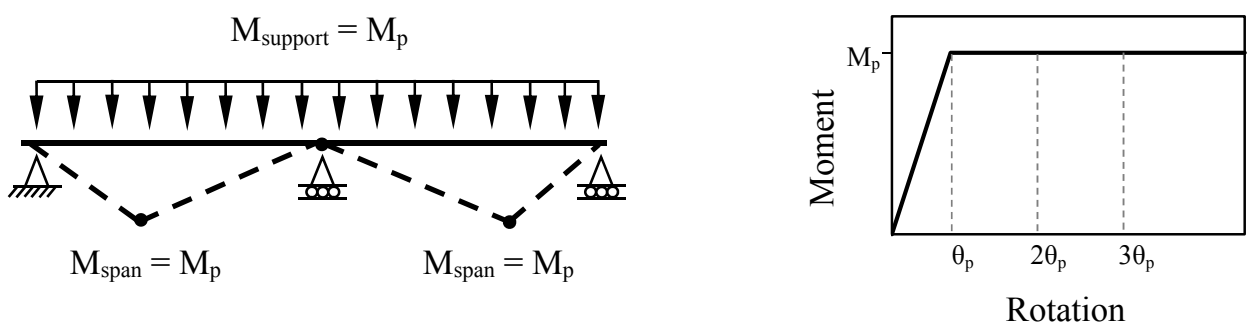

Fig. 2. Idealised full moment redistribution in a 2-span system and elastic, plastic momentrotation relationship 


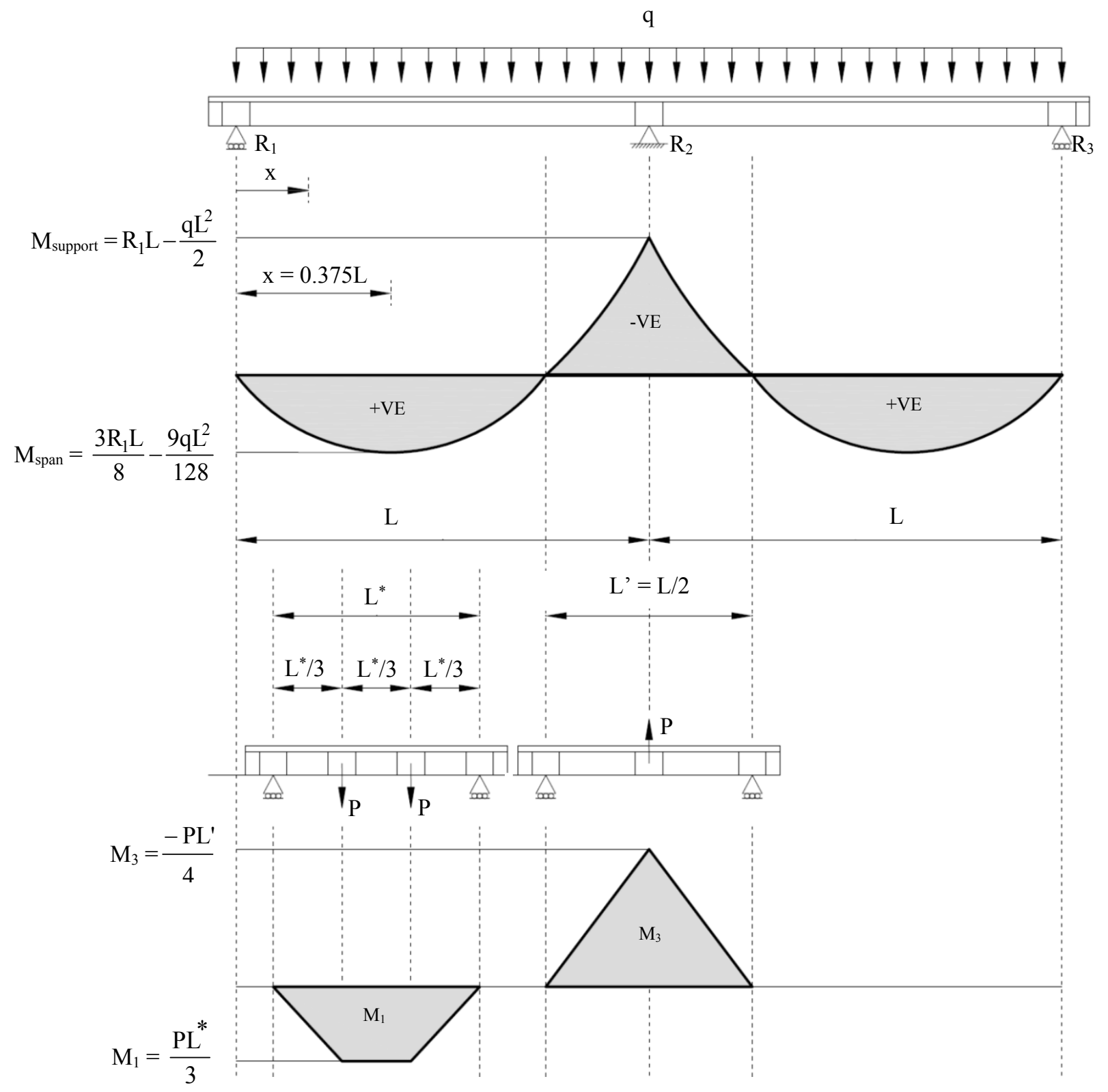

Fig. 3. Elastic bending moment diagram (BMD) for 2-span purlin system, together with reference $\mathrm{M}_{1}$ and $\mathrm{M}_{3}$ moments from single span arrangements 


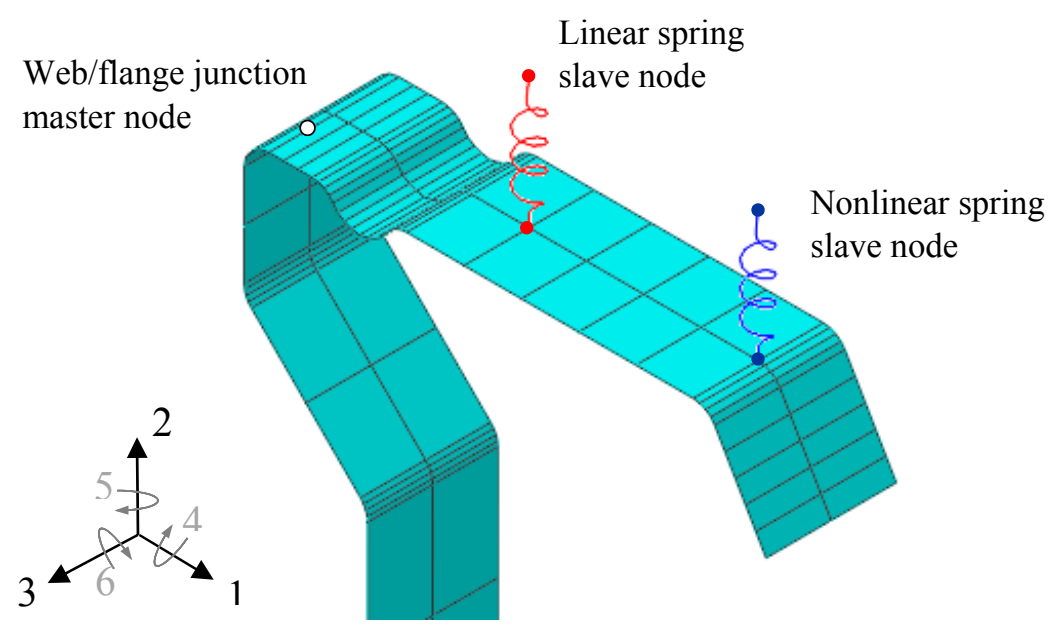

Fig. 4. Two-spring model to represent sheeting

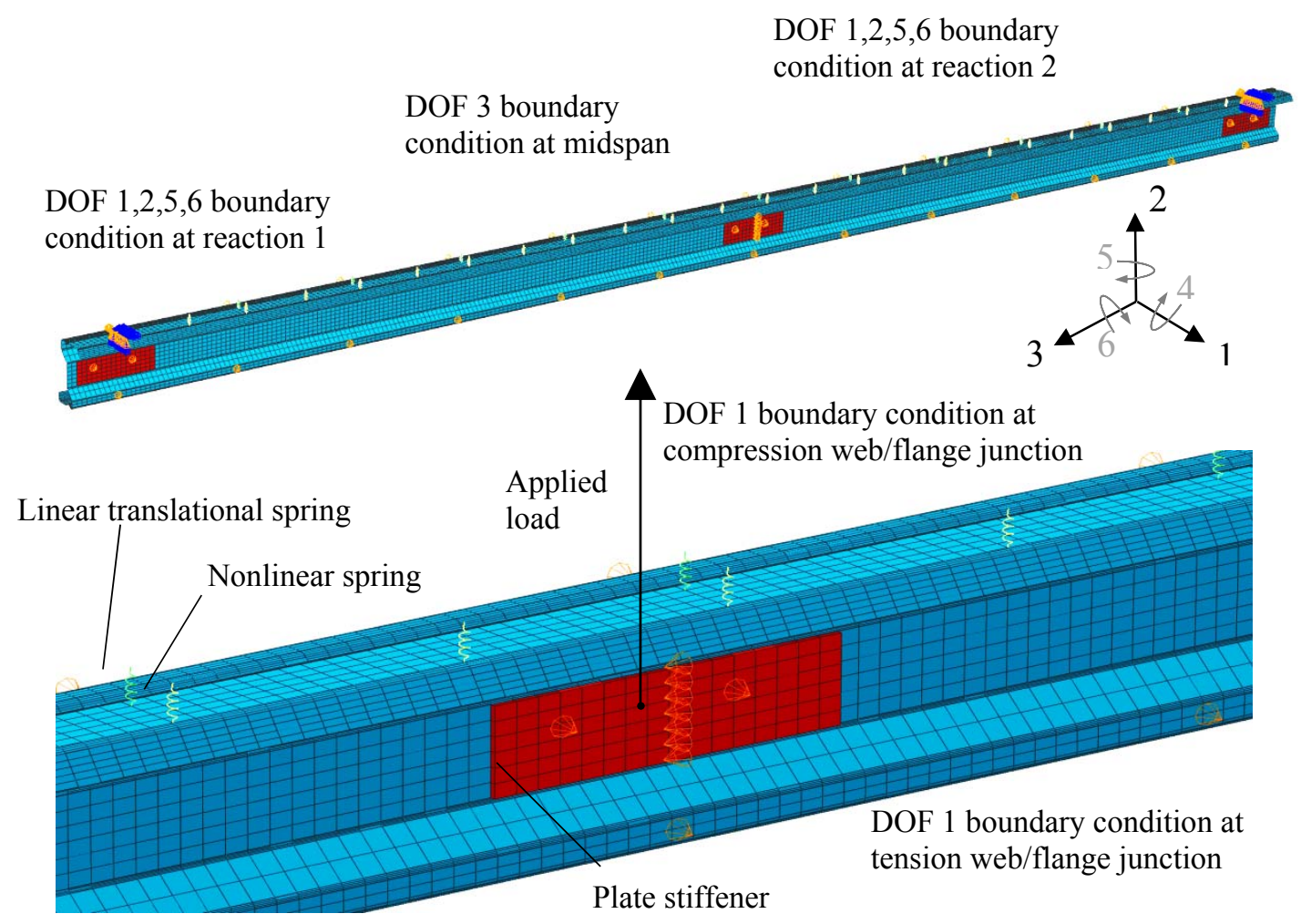

Fig. 5. FE model of 3-point bending arrangement, used to obtain $\mathrm{M}_{3}$ 


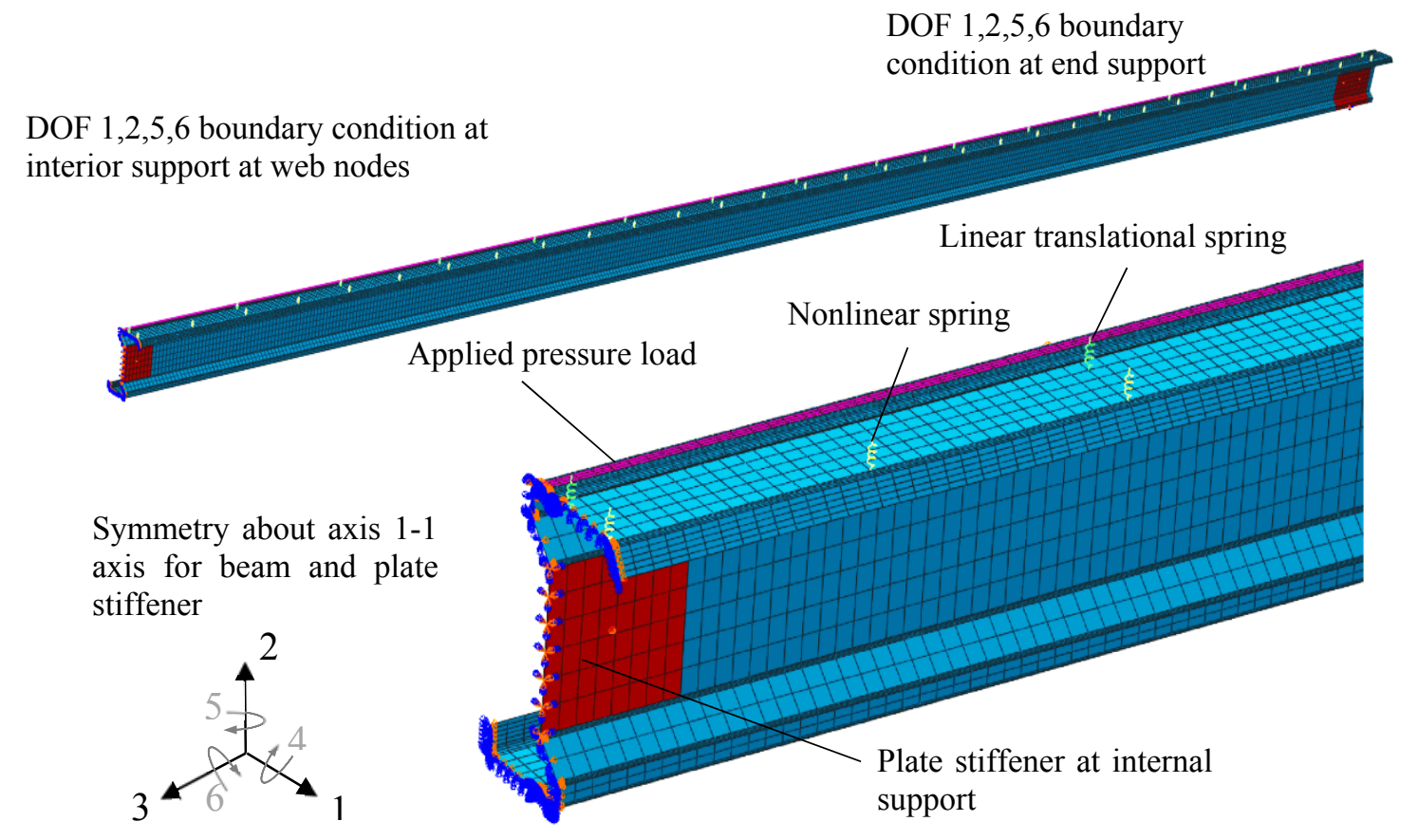

Fig. 6. FE model of 2-span continuous purlin system

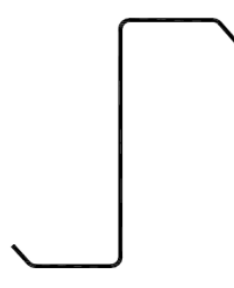

(a)

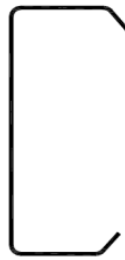

(b)

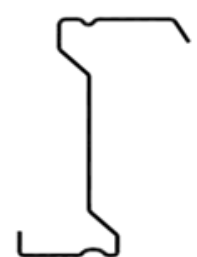

(c)

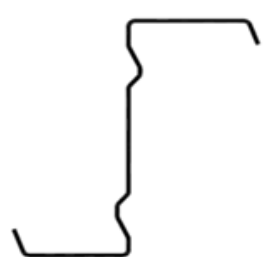

(d)

Fig. 7. Cold-formed steel cross-section shapes: (a) Zed, (b) Channel, (c) Zeta I and (d) Zeta II 


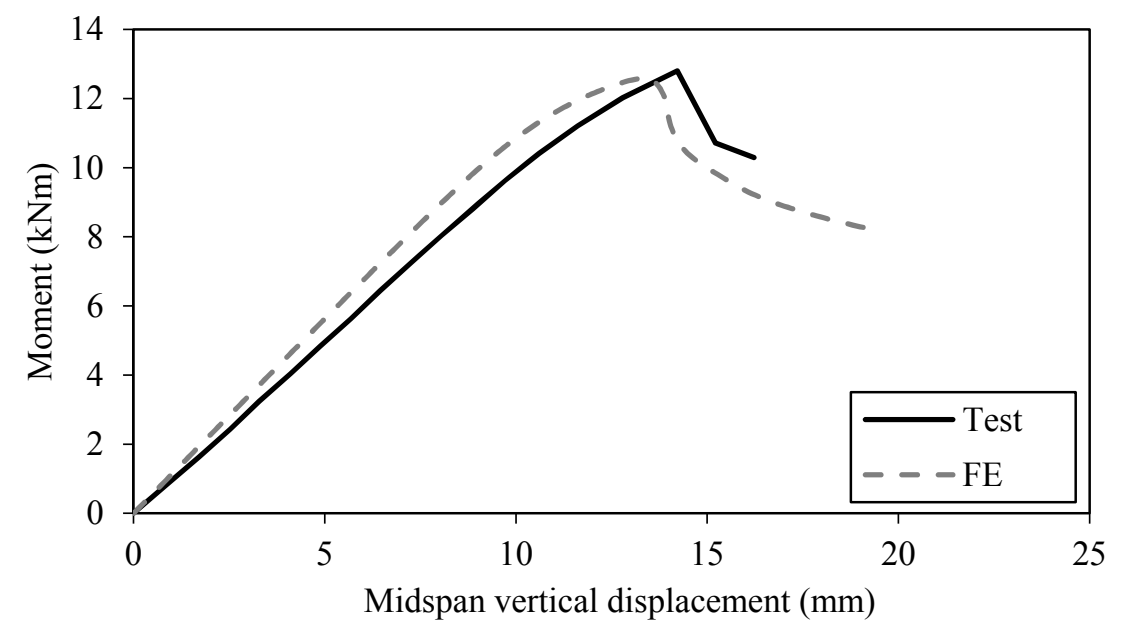

(a) Test 11

Fig.8. Comparison of test moment-deflection response for a Zeta II section in 3-point bending from [27] with that obtained from the FE model

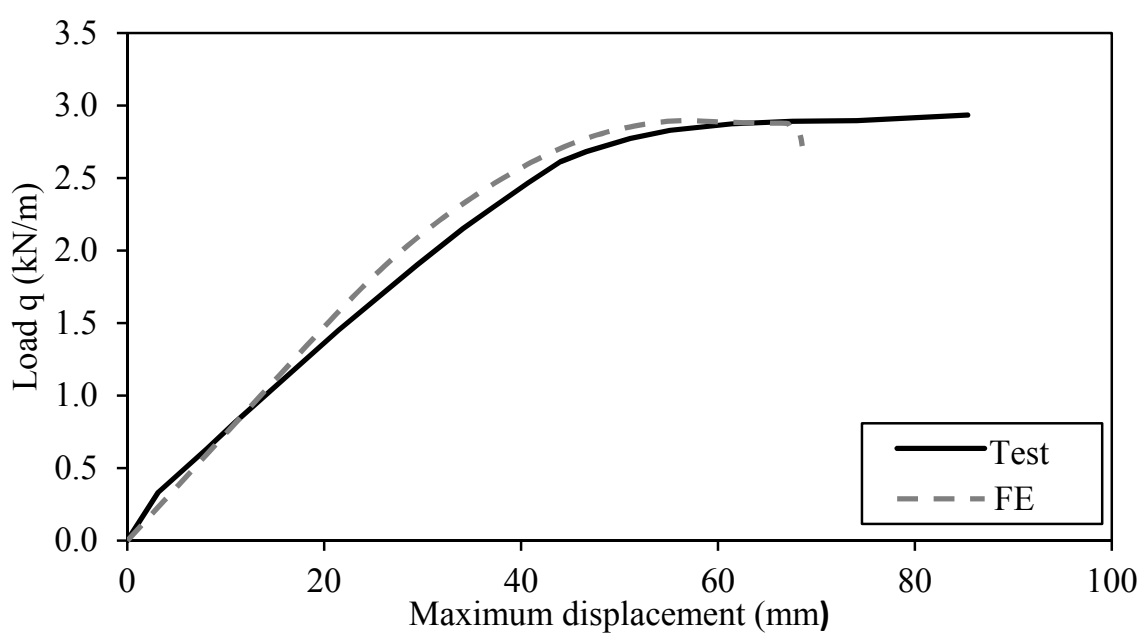

Fig.9. Comparison of the test load-deformation curve for a Zeta I section in a 2-span arrangement from [22] with that obtained from the FE model 

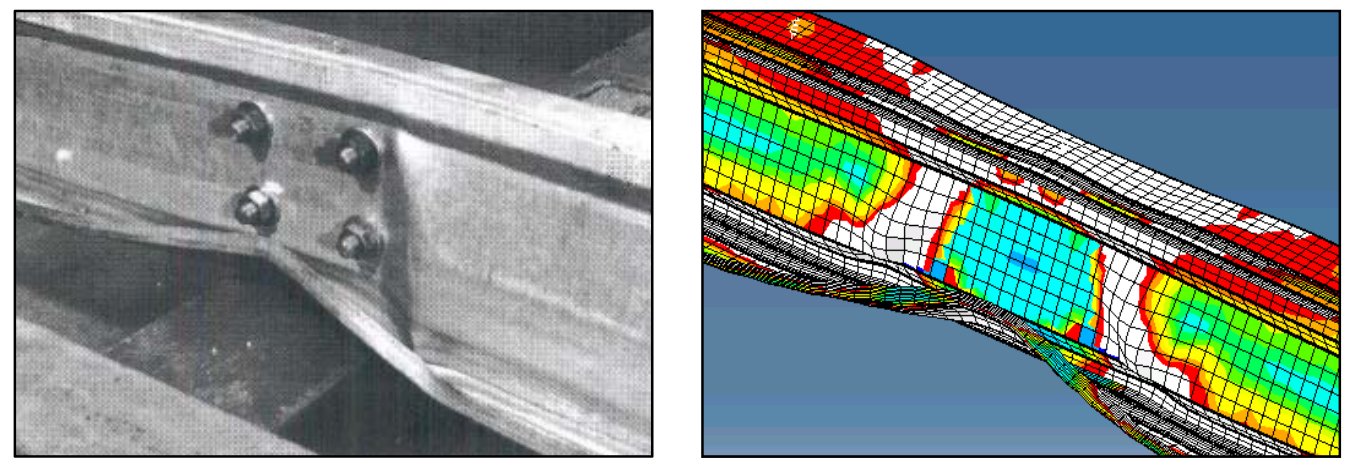

(a)
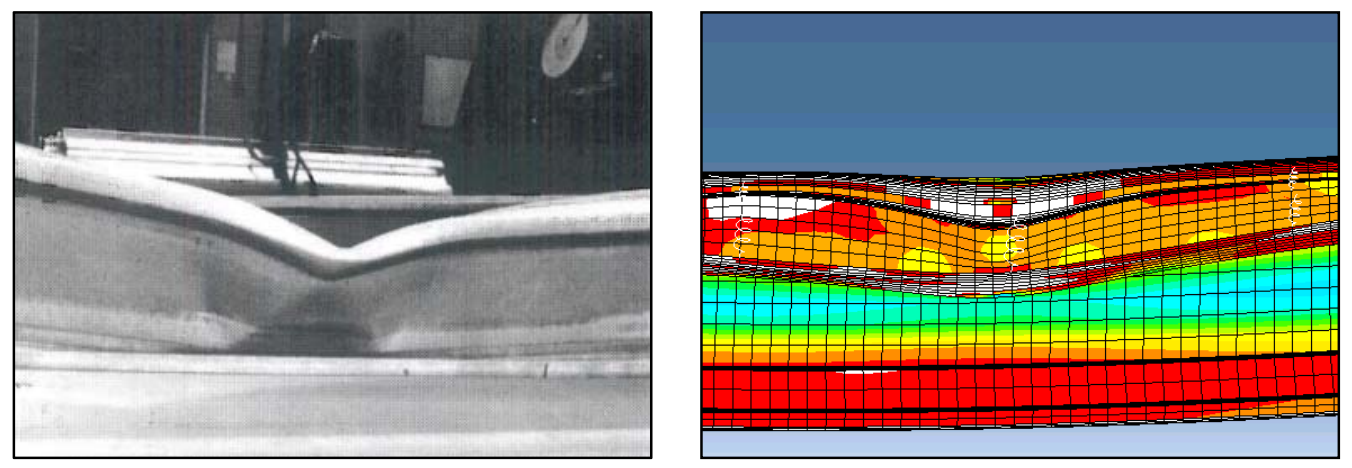

(b)

Fig. 10. Comparison of failure modes between physical test [23] at the (a) support and (b) span

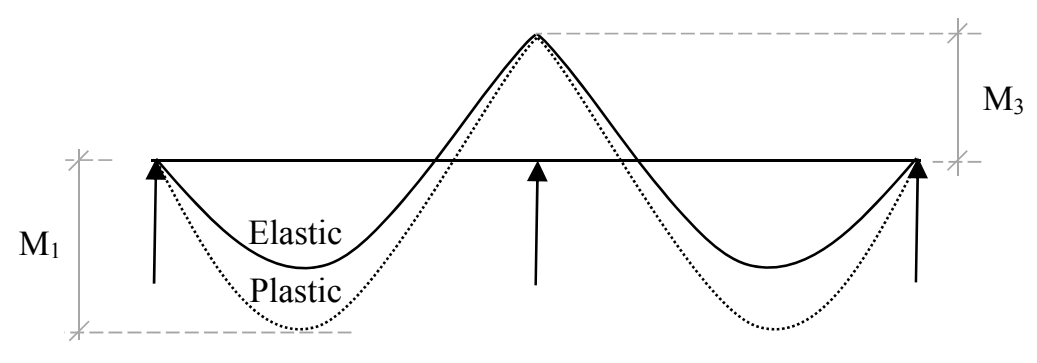

Fig. 11. Bending moment diagram at the ultimate system load for an ideal situation of full redistribution with no moment drop-off at the interior support 


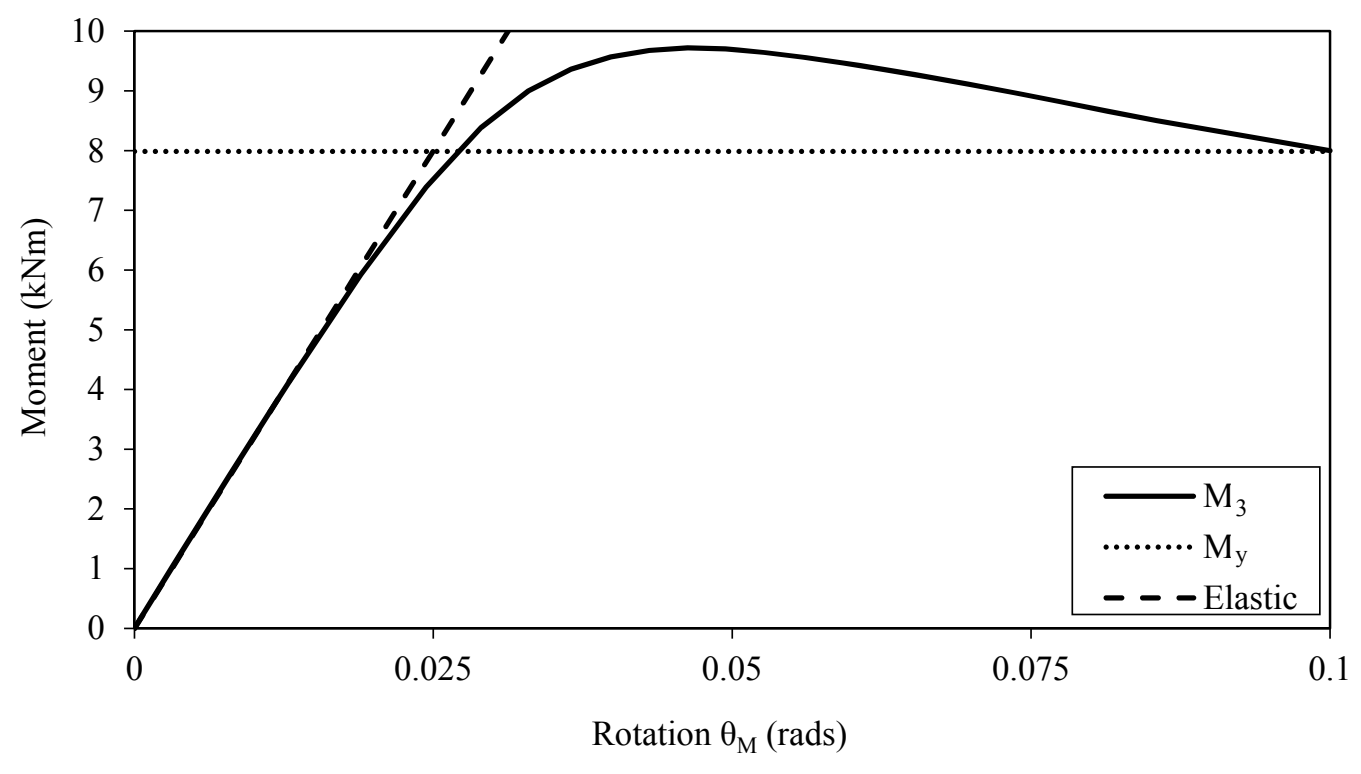

Fig. 12. Typical moment-rotation $(\mathrm{M}-\theta)$ response for stocky sections

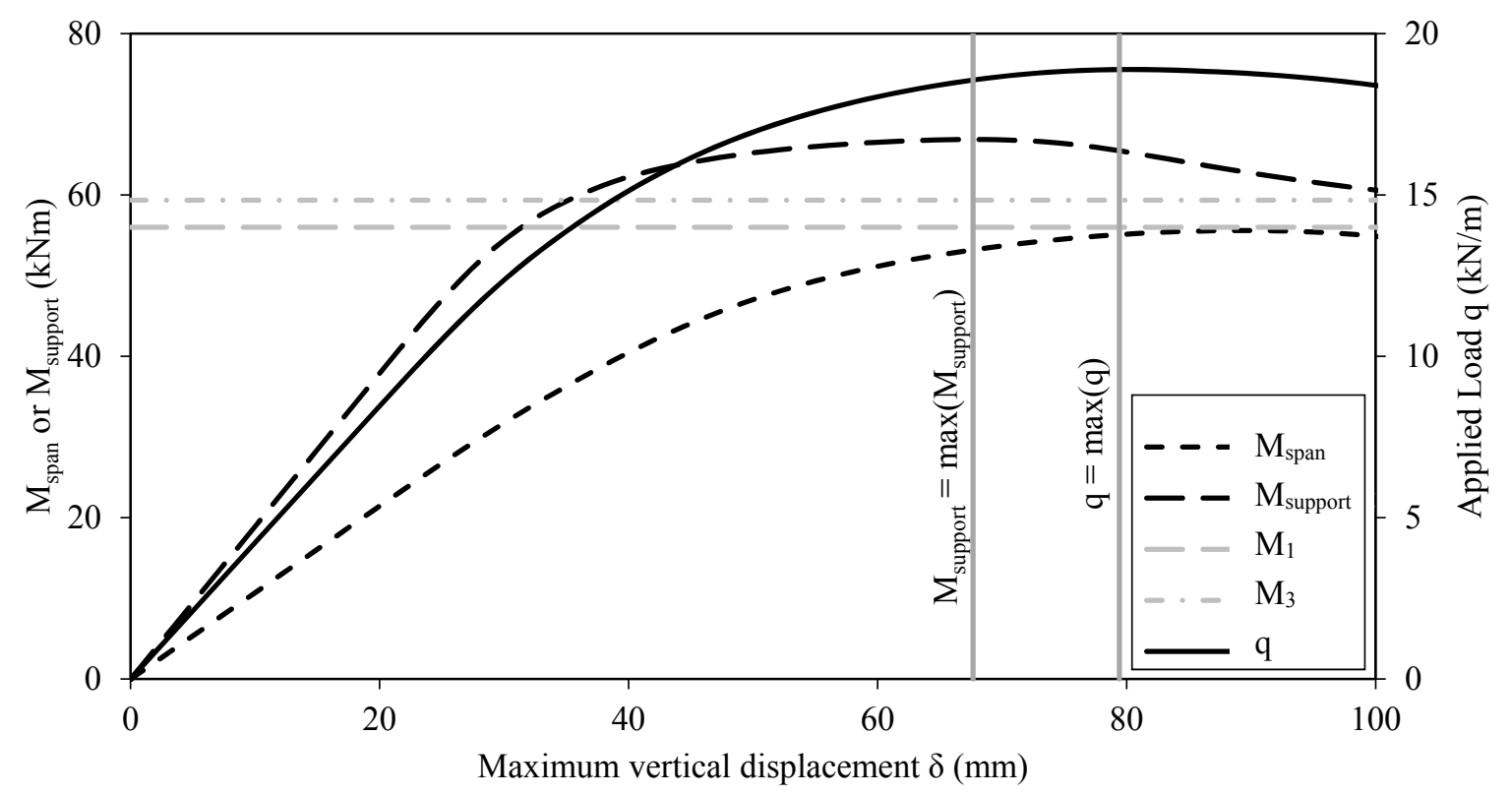

Fig. 13: Typical support/ span moment versus maximum vertical displacement responses for a 2-span continuous purlin system comprising stocky cross-sections 


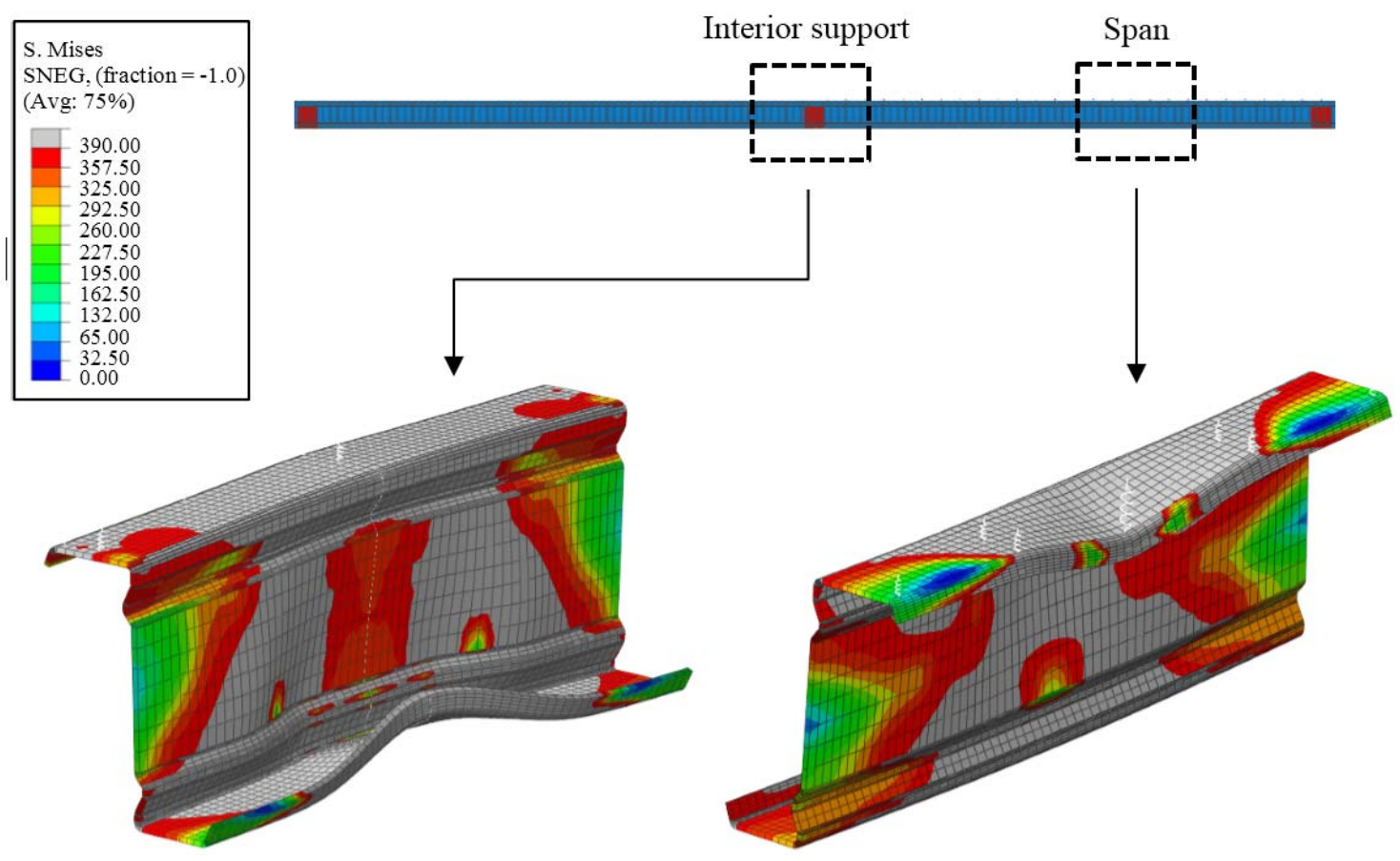

Fig. 14. Deformed von Mises stress profiles for 2-span 2/225_50 L $=6 \mathrm{~m}$ FE model at ultimate load 


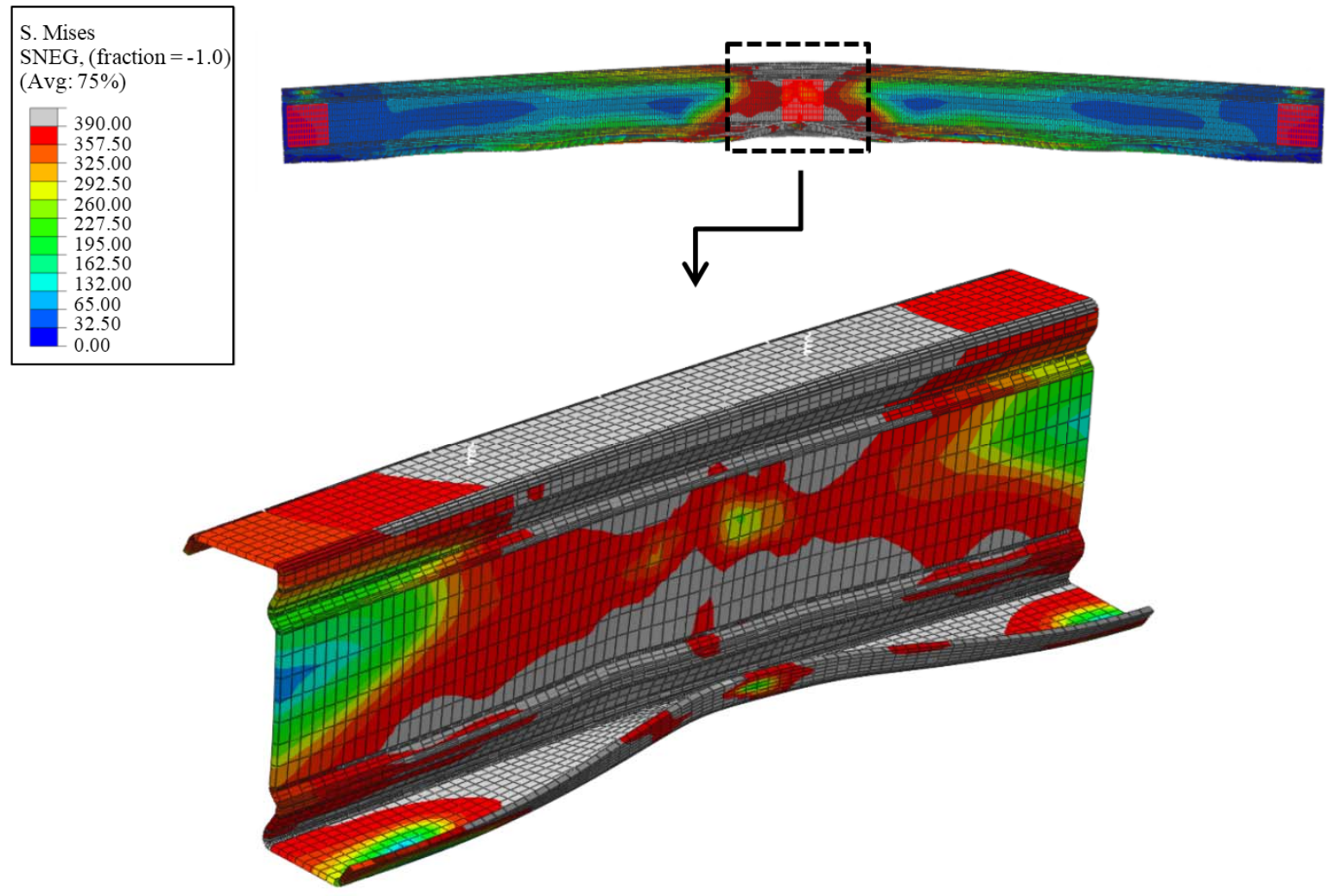

Fig. 15. Deformed von Mises stress profile for $\mathrm{M}_{1} 2 / 225 \_50 \mathrm{~L}^{*}=4880 \mathrm{~mm}$
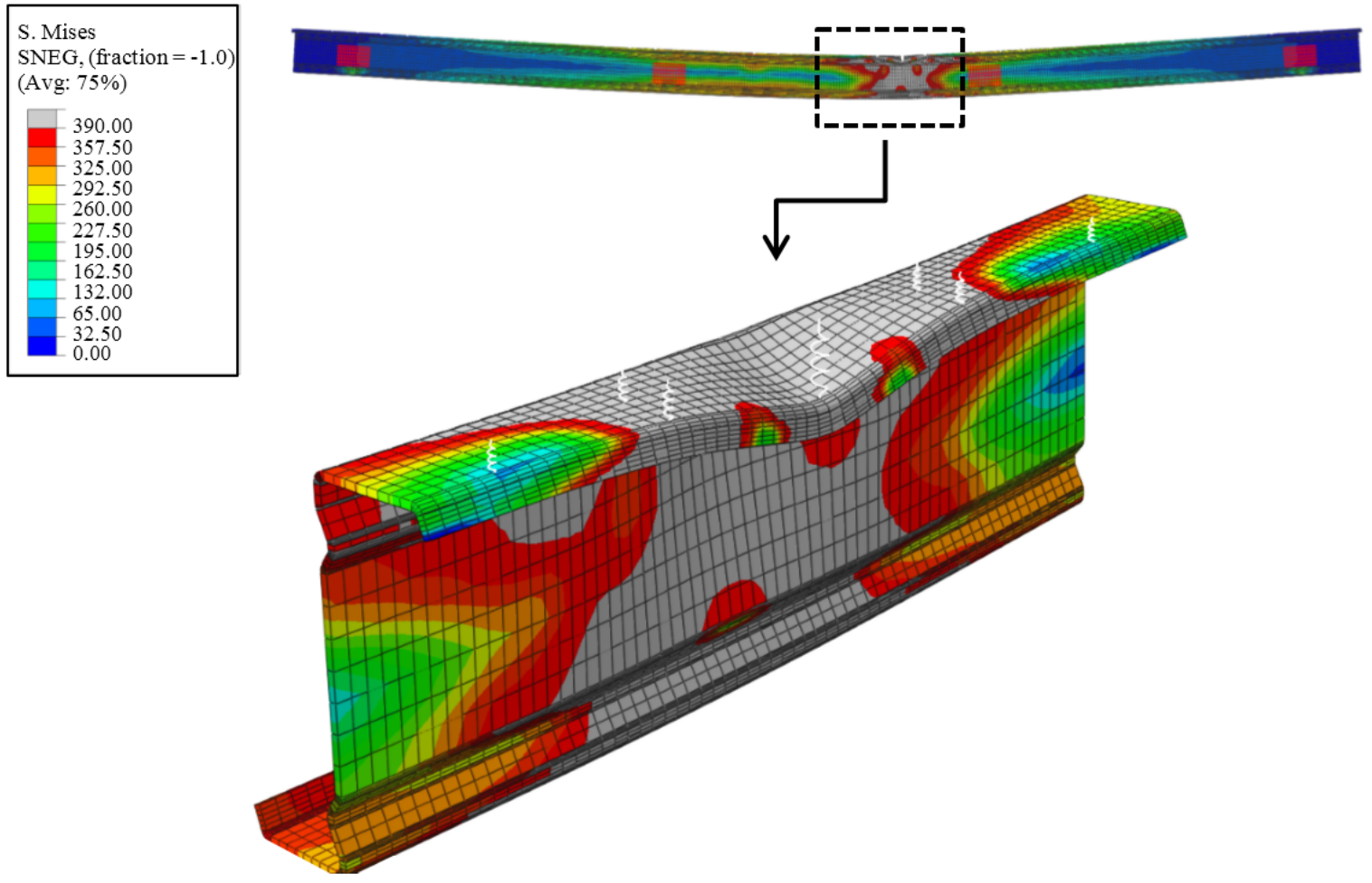

Fig. 16. Deformed von Mises stress profile for M3 2/225_50 L' $=3000 \mathrm{~mm}$ 


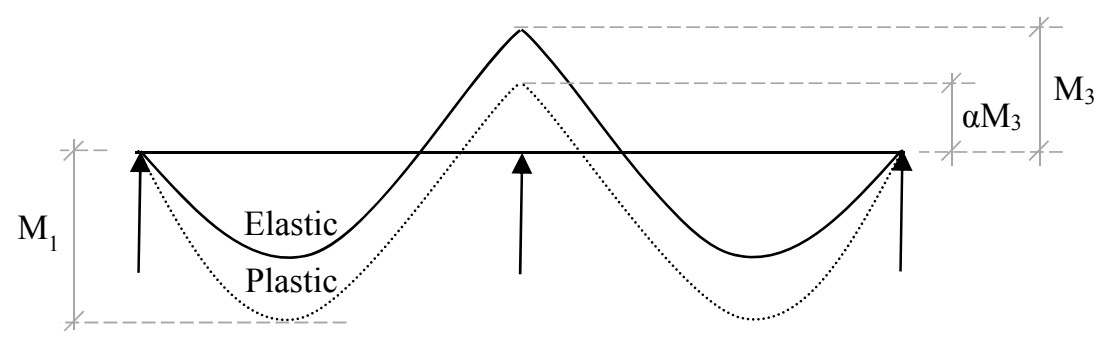

Fig. 17: Bending moment diagram at the ultimate system load for 2-span purlins with slender cross-sections, showing moment drop-off at the interior support

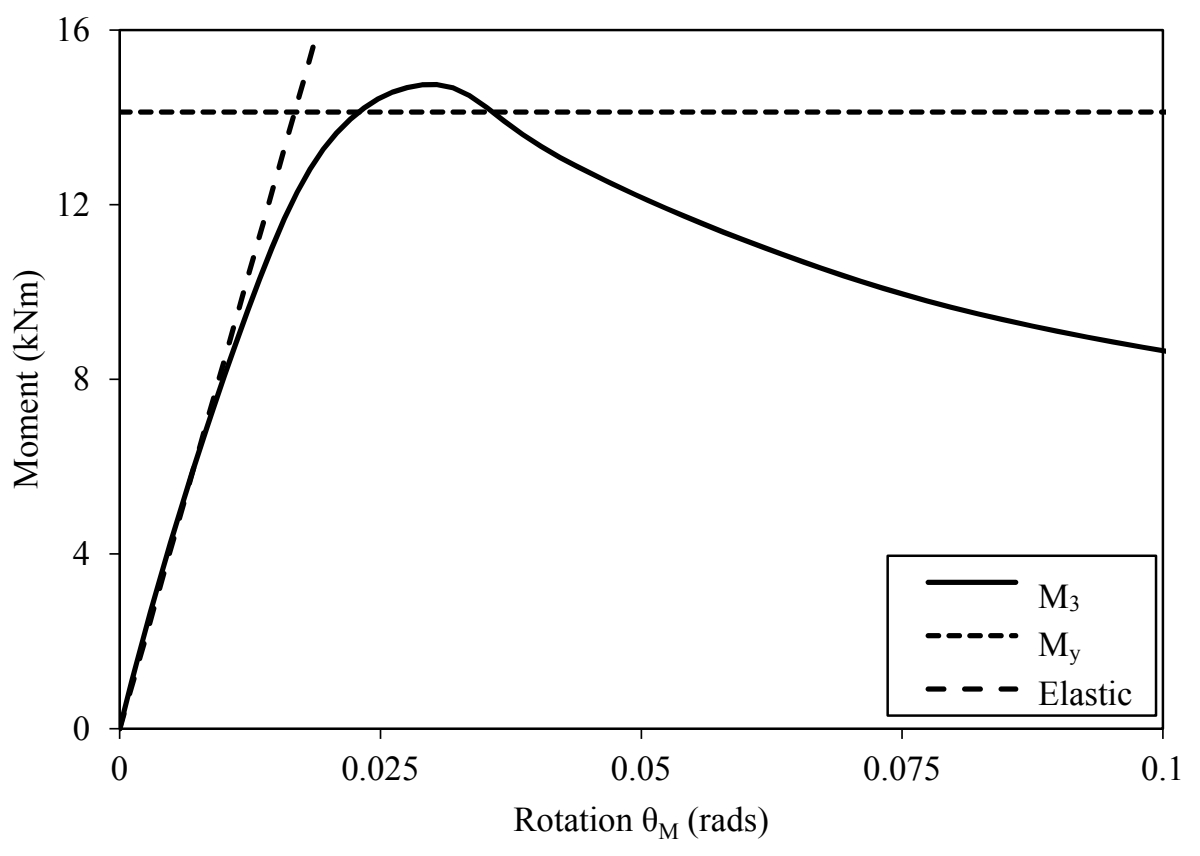

Fig.18. Typical moment-rotation (M- $\theta)$ response for slender sections 


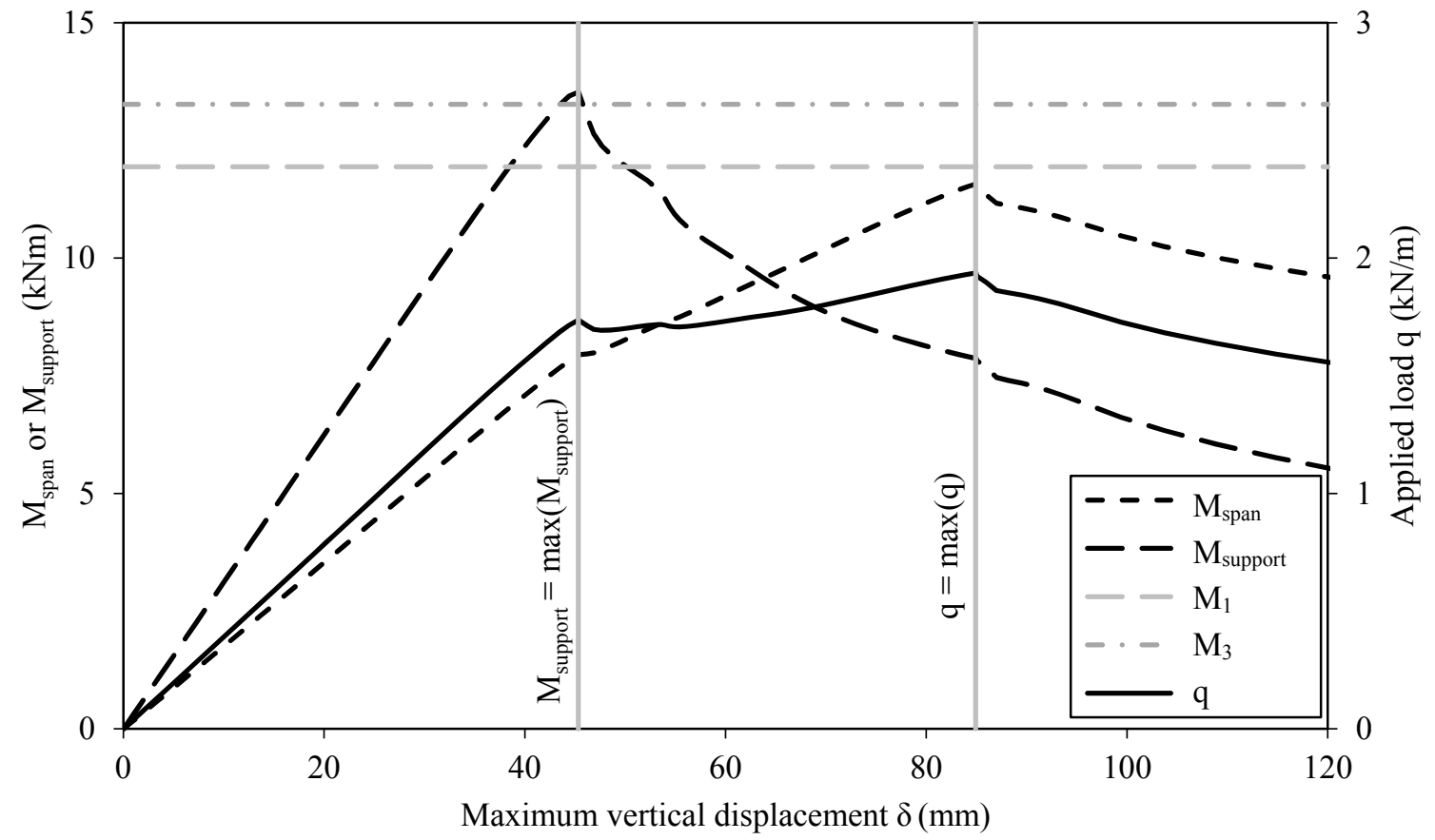

Fig. 19. Typical support/ span moment versus maximum vertical displacement responses for a 2-span continuous purlin system comprising slender cross-sections

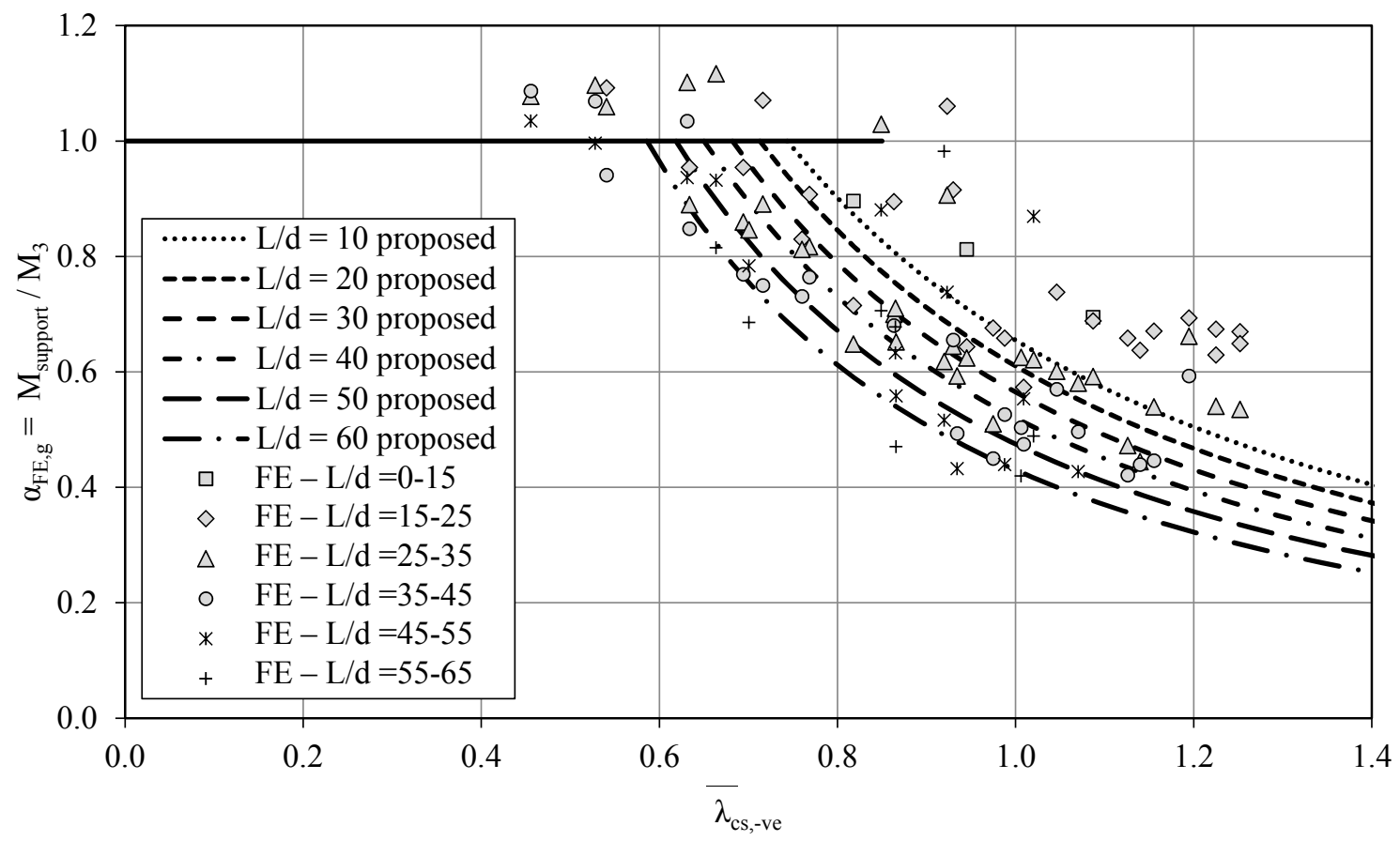

Fig. 20. Support moment reduction versus cross-section slenderness 
Table 1: Summary of single span and 2-span FE model validation

\begin{tabular}{|c|c|c|c|c|c|}
\hline Reference & Test type & $\begin{array}{l}\text { Section } \\
\text { Type }\end{array}$ & $\begin{array}{l}\text { No. of } \\
\text { tests }\end{array}$ & $\begin{array}{c}\text { Mean } \\
\mathrm{q}_{\mathrm{FE}} / \mathrm{q}_{\text {test }}\end{array}$ & $\mathrm{COV}$ \\
\hline Wang and Zhang [20] & 4-point (pure) bending & $\mathrm{C}$ & 4 & 0.993 & 0.020 \\
\hline Yu and Schafer [21] & 4-point (pure) bending & $\mathrm{Zed} / \mathrm{C}$ & 25 & 1.003 & 0.055 \\
\hline Wang and Zhang [20] & 3-point bending & $\mathrm{C}$ & 4 & 1.006 & 0.009 \\
\hline $\begin{array}{l}\text { Bryan and Davies }[22,23] \\
\text { Bryan and Deakin }[24] \\
\text { Deakin }[25,26]\end{array}$ & 3-point bending & $\begin{array}{l}\text { Zeta IA } \\
\text { Zeta IB }\end{array}$ & 7 & 0.995 & 0.043 \\
\hline Davies and Deakin [27] & 3-point bending & Zeta II & 5 & 0.994 & 0.017 \\
\hline Bryan and Davies $[22,23]$ & & Zeta IA & & & \\
\hline Bryan and Deakin [24] & 2-span gravity & Zeta IB & 10 & 1.013 & 0.030 \\
\hline Deakin $[25,26]$ & & Zeta IC & & & \\
\hline $\begin{array}{l}\text { Deakin }[25,26] \\
\text { Deakin et al. [28] }\end{array}$ & 2-span uplift & Zeta IB & 6 & 1.015 & 0.028 \\
\hline Total & & & 61 & 1.004 & 0.041 \\
\hline
\end{tabular}


Table 2: List of dimensions for Zeta I, Zeta II, Zed and channel sections

\begin{tabular}{|c|c|c|c|c|c|c|c|}
\hline $\begin{array}{l}\text { Section } \\
\text { Type }\end{array}$ & $\begin{array}{c}\text { Section } \\
\text { Reference }\end{array}$ & $\begin{array}{c}\text { Top flange } \\
b_{\mathrm{c}} \\
(\mathrm{mm})\end{array}$ & $\begin{array}{c}\text { Bottom flange } \\
b_{t} \\
(\mathrm{~mm})\end{array}$ & $\begin{array}{l}\text { Height } \\
\text { h } \\
(\mathrm{mm})\end{array}$ & $\begin{array}{c}\text { Thickness } \\
t \\
(\mathrm{~mm})\end{array}$ & $\bar{\lambda}_{\mathrm{cs}, \mathrm{ve}}$ & $\overline{\bar{\lambda}}_{\mathrm{cs},-\mathrm{ve}}$ \\
\hline Zeta I & 1/150_50 & 72 & 65 & 150 & 5.0 & 0.617 & 0.455 \\
\hline Zeta I & 1/150_40 & 72 & 65 & 150 & 4.0 & 0.811 & 0.528 \\
\hline Zeta I & 1/150_30 & 72 & 65 & 150 & 3.0 & 0.832 & 0.632 \\
\hline Zeta I & 1/125_20 & 72 & 65 & 125 & 2.0 & 0.950 & 0.631 \\
\hline Zeta I & 1/200_25 & 72 & 65 & 200 & 2.5 & 0.976 & 0.716 \\
\hline Zeta I & $1 / 125 \_13$ & 60 & 50 & 125 & 1.3 & 1.042 & 0.849 \\
\hline Zeta I & $1 / 175 \quad 16$ & 72 & 65 & 175 & 1.6 & 1.083 & 0.923 \\
\hline Zeta I & $1 / 200 \quad 16$ & 72 & 65 & 200 & 1.6 & 1.084 & 0.930 \\
\hline Zeta I & $1 / 200 \quad 13$ & 72 & 65 & 200 & 1.3 & 1.220 & 1.046 \\
\hline Zeta II & $2 / 225 \quad 50$ & 78 & 68 & 225 & 5.0 & 0.590 & 0.541 \\
\hline Zeta II & 2/225_40 & 78 & 68 & 225 & 4.0 & 0.691 & 0.634 \\
\hline Zeta II & 2/225_35 & 78 & 68 & 225 & 3.5 & 0.757 & 0.694 \\
\hline Zeta II & 2/225_30 & 78 & 68 & 225 & 3.0 & 0.762 & 0.768 \\
\hline Zeta II & 2/285_30 & 78 & 68 & 285 & 3.0 & 0.832 & 0.818 \\
\hline Zeta II & $2 / 225 \quad 25$ & 78 & 68 & 225 & 2.5 & 0.855 & 0.863 \\
\hline Zeta II & $2 / 285 \quad 25$ & 78 & 68 & 285 & 2.5 & 0.936 & 0.945 \\
\hline Zeta II & $2 / 285 \quad 20$ & 78 & 68 & 285 & 2.0 & 1.056 & 1.087 \\
\hline Zeta II & $2 / 225 \quad 14$ & 78 & 68 & 225 & 1.4 & 1.205 & 1.195 \\
\hline Zeta II & $2 / 245 \quad 15$ & 78 & 68 & 245 & 1.5 & 1.195 & 1.225 \\
\hline Zeta II & 2/265_15 & 78 & 68 & 265 & 1.5 & 1.233 & 1.252 \\
\hline Zed & Z/125_20 & 55 & 45 & 125 & 2.0 & 0.778 & 0.700 \\
\hline Zed & Z/200_25 & 58 & 49 & 200 & 2.5 & 0.806 & 0.760 \\
\hline Zed & $\mathrm{Z} / 125$ & 55 & 45 & 125 & 1.4 & 0.957 & 0.865 \\
\hline Zed & $\mathrm{Z} / 155$ & 58 & 49 & 155 & 1.5 & 1.016 & 0.934 \\
\hline Zed & $\mathrm{Z} / 170 \_14$ & 58 & 49 & 170 & 1.4 & 1.087 & 1.009 \\
\hline Zed & $\mathrm{Z} / 200 \quad 13$ & 58 & 49 & 200 & 1.3 & 1.202 & 1.140 \\
\hline $\mathrm{C}$ & $\mathrm{C} / 12720$ & 65 & 65 & 127 & 2.0 & 0.857 & 0.866 \\
\hline $\mathrm{C}$ & C/127_18 & 65 & 65 & 127 & 1.8 & 0.911 & 0.920 \\
\hline $\mathrm{C}$ & $\mathrm{C} / 200 \_20$ & 65 & 65 & 200 & 2.0 & 0.968 & 0.975 \\
\hline $\mathrm{C}$ & $\mathrm{C} / 170 \_18$ & 65 & 65 & 170 & 1.8 & 0.979 & 0.988 \\
\hline $\mathrm{C}$ & $\mathrm{C} / 140 \_16$ & 65 & 65 & 140 & 1.6 & 0.996 & 1.006 \\
\hline $\mathrm{C}$ & $\mathrm{C} / 127 \_15$ & 65 & 65 & 127 & 1.5 & 1.010 & 1.020 \\
\hline $\mathrm{C}$ & $\mathrm{C} / 155 \_15$ & 65 & 65 & 155 & 1.5 & 1.061 & 1.070 \\
\hline $\mathrm{C}$ & $\mathrm{C} / 185 \quad 15$ & 65 & 65 & 185 & 1.5 & 1.117 & 1.126 \\
\hline $\mathrm{C}$ & $\mathrm{C} / 200 \quad 15$ & 65 & 65 & 200 & 1.5 & 1.147 & 1.155 \\
\hline
\end{tabular}


Table 3. $\mathrm{M}_{\text {span }}$ and $\mathrm{M}_{\text {support }}$ inputs values for Equation 4.8 for design methods 1, 2 and 3

\begin{tabular}{llccc}
\hline & Design method & $\mathrm{M}_{\text {span }}$ & $\mathrm{M}_{\text {support }}$ & Eq. 1 \\
\hline 1 & Elastic design & $0.5625 \mathrm{M}_{3}$ & $\mathrm{M}_{3}$ & $0.5625 \mathrm{M}_{3}=\frac{\left(\mathrm{q}_{1 \mathrm{~g}} \mathrm{~L}^{2}+2 \mathrm{M}_{3}\right)^{2}}{8 \mathrm{q}_{1 \mathrm{~g}} \mathrm{~L}^{2}}$ \\
\hline $\begin{array}{l}\text { Full plastic } \\
\text { redistribution }\end{array}$ & $\mathrm{M}_{1}$ & $\mathrm{M}_{3}$ & $\mathrm{M}_{1}=\frac{\left(\mathrm{q}_{2 \mathrm{~g}} \mathrm{~L}^{2}+2 \mathrm{M}_{3}\right)^{2}}{8 \mathrm{q}_{2 \mathrm{~g}} \mathrm{~L}^{2}}$ \\
\hline & $\mathrm{M}_{1}$ & $\alpha_{\text {design,g }} \mathrm{M}_{3}$ & $\mathrm{M}_{1}=\frac{\left(\mathrm{q}_{3 \mathrm{~g}} \mathrm{~L}^{2}+2 \alpha_{\text {design,g }} \mathrm{M}_{3}\right)^{2}}{8 \mathrm{q}_{3 \mathrm{~g}} \mathrm{~L}^{2}}$ \\
\hline
\end{tabular}


Table 4. Ultimate load comparison between 2-span FE results and design methods 1, 2 and 3 for span length $L=4,6$ and $8 \mathrm{~m}$

\begin{tabular}{|c|c|c|c|c|c|c|c|c|c|c|c|c|}
\hline \multirow[b]{2}{*}{$\begin{array}{l}\text { Section } \\
\text { reference }\end{array}$} & \multicolumn{4}{|c|}{$\mathrm{L}=4 \mathrm{~m}$} & \multicolumn{4}{|c|}{$\mathrm{L}=6 \mathrm{~m}$} & \multicolumn{4}{|c|}{$\mathrm{L}=8 \mathrm{~m}$} \\
\hline & $\begin{array}{c}\mathrm{q}_{\mathrm{FE}, \mathrm{g}} \\
(\mathrm{kN} / \mathrm{m})\end{array}$ & $\begin{array}{c}\mathrm{q}_{1, \mathrm{~g}} \\
(\mathrm{kN} / \mathrm{m})\end{array}$ & $\begin{array}{c}\mathrm{q}_{2, \mathrm{~g}} \\
(\mathrm{kN} / \mathrm{m})\end{array}$ & $\begin{array}{c}\mathrm{q}_{3, \mathrm{~g}} \\
(\mathrm{kN} / \mathrm{m})\end{array}$ & $\begin{array}{c}\mathrm{q}_{\mathrm{FE}, \mathrm{g}} \\
(\mathrm{kN} / \mathrm{m})\end{array}$ & $\begin{array}{c}\mathrm{q}_{1, \mathrm{~g}} \\
(\mathrm{kN} / \mathrm{m})\end{array}$ & $\begin{array}{c}\mathrm{q}_{2, \mathrm{~g}} \\
(\mathrm{kN} / \mathrm{m})\end{array}$ & $\begin{array}{c}\mathrm{q}_{3, \mathrm{~g}} \\
(\mathrm{kN} / \mathrm{m})\end{array}$ & $\begin{array}{c}\mathrm{q}_{\mathrm{FE}, \mathrm{g}} \\
(\mathrm{kN} / \mathrm{m})\end{array}$ & $\begin{array}{c}\mathrm{q}_{1, \mathrm{~g}} \\
(\mathrm{kN} / \mathrm{m})\end{array}$ & $\begin{array}{c}\mathrm{q}_{2, \mathrm{~g}} \\
(\mathrm{kN} / \mathrm{m})\end{array}$ & $\begin{array}{c}\mathrm{q}_{3, \mathrm{~g}} \\
(\mathrm{kN} / \mathrm{m})\end{array}$ \\
\hline 1/150_50 & 23.603 & 18.533 & 24.860 & 24.860 & 11.615 & 8.359 & 11.100 & 11.100 & 6.451 & 4.709 & 6.247 & 6.247 \\
\hline 1/150_40 & 20.966 & 15.105 & 20.132 & 20.132 & 9.175 & 6.599 & 8.900 & 8.900 & 5.020 & 3.570 & 4.946 & 4.946 \\
\hline 1/150_30 & 15.289 & 10.795 & 14.809 & 14.809 & 6.627 & 4.716 & 6.547 & 6.547 & 3.598 & 2.676 & 3.693 & 3.620 \\
\hline 1/125_20 & 6.951 & 5.022 & 6.760 & 6.760 & 2.933 & 2.157 & 2.973 & 2.880 & 1.576 & 1.229 & 1.679 & 1.555 \\
\hline 1/200_25 & 18.535 & 13.154 & 18.025 & 17.986 & 7.767 & 5.833 & 8.005 & 7.840 & 4.165 & 3.241 & 4.486 & 4.298 \\
\hline $1 / 125 \_13$ & 4.030 & 2.911 & 4.015 & 3.613 & 1.725 & 1.324 & 1.797 & 1.565 & 0.913 & 0.730 & 1.005 & 0.847 \\
\hline $1 / 175 \_16$ & 8.694 & 6.150 & 8.561 & 7.617 & 3.759 & 2.812 & 3.838 & 3.347 & 2.007 & 1.587 & 2.161 & 1.845 \\
\hline 1/200_16 & 9.965 & 7.632 & 10.392 & 9.251 & 4.227 & 3.343 & 4.598 & 4.039 & 2.327 & 1.873 & 2.583 & 2.231 \\
\hline 1/200_13 & 7.020 & 5.950 & 7.969 & 6.788 & 3.092 & 2.634 & 3.537 & 2.975 & 1.763 & 1.474 & 1.987 & 1.646 \\
\hline 2/225_50 & 43.983 & 29.725 & 41.544 & 41.544 & 18.886 & 13.191 & 18.455 & 18.455 & 10.246 & 7.416 & 10.379 & 10.379 \\
\hline $2 / 225 \_40$ & 34.429 & 25.571 & 33.479 & 33.479 & 14.304 & 10.729 & 14.612 & 14.612 & 7.904 & 5.874 & 8.151 & 8.151 \\
\hline 2/225_35 & 29.856 & 22.085 & 29.253 & 29.253 & 12.229 & 9.284 & 12.777 & 12.760 & 6.617 & 5.250 & 7.199 & 7.057 \\
\hline 2/225_30 & 24.578 & 18.591 & 24.560 & 23.848 & 10.117 & 7.828 & 10.733 & 10.254 & 5.557 & 4.408 & 6.039 & 5.668 \\
\hline $2 / 285 \_30$ & 32.346 & 24.729 & 33.750 & 32.180 & 13.609 & 11.035 & 15.018 & 14.134 & 7.484 & 6.172 & 8.433 & 7.834 \\
\hline $2 / 225 \_25$ & 19.606 & 15.051 & 19.861 & 18.372 & 7.962 & 6.484 & 8.740 & 7.965 & 4.423 & 3.560 & 4.880 & 4.380 \\
\hline $2 / 285 \_25$ & 25.193 & 20.283 & 27.340 & 24.649 & 10.868 & 9.327 & 12.283 & 10.913 & 5.995 & 5.031 & 6.818 & 6.002 \\
\hline 2/285_20 & 17.570 & 14.385 & 20.305 & 17.577 & 8.079 & 6.336 & 9.000 & 7.715 & 4.414 & 3.558 & 5.060 & 4.292 \\
\hline $2 / 225 \_14$ & 7.860 & 7.022 & 9.144 & 7.557 & 3.543 & 3.041 & 4.030 & 3.296 & 1.936 & 1.659 & 2.245 & 1.819 \\
\hline $2 / 245 \_15$ & 9.741 & 8.593 & 11.295 & 9.305 & 4.334 & 3.758 & 4.994 & 4.072 & 2.368 & 2.103 & 2.805 & 2.261 \\
\hline $2 / 265 \_15$ & 10.106 & 8.506 & 12.121 & 10.090 & 4.719 & 3.963 & 5.464 & 4.474 & 2.569 & 2.215 & 3.068 & 2.487 \\
\hline $\mathrm{Z} / 125 \_20$ & 5.109 & 4.217 & 5.655 & 5.560 & 2.171 & 1.844 & 2.500 & 2.374 & 1.177 & 1.038 & 1.407 & 1.285 \\
\hline Z/200_25 & 12.780 & 9.952 & 13.739 & 13.362 & 5.666 & 4.420 & 6.105 & 5.823 & 3.041 & 2.486 & 3.434 & 3.210 \\
\hline $\mathrm{Z} / 125 \_14$ & 3.188 & 2.684 & 3.640 & 3.284 & 1.351 & 1.195 & 1.619 & 1.415 & 0.767 & 0.663 & 0.906 & 0.768 \\
\hline $\mathrm{Z} / 155 \_15$ & 4.760 & 3.878 & 5.348 & 4.754 & 1.994 & 1.714 & 2.373 & 2.063 & 1.074 & 0.959 & 1.332 & 1.132 \\
\hline $\mathrm{Z} / 170 \_14$ & 4.855 & 3.902 & 5.395 & 4.695 & 2.009 & 1.715 & 2.389 & 2.041 & 1.148 & 0.957 & 1.341 & 1.124 \\
\hline Z/200_13 & 5.449 & 4.176 & 5.738 & 4.836 & 2.160 & 1.870 & 2.557 & 2.119 & 1.184 & 1.040 & 1.433 & 1.171 \\
\hline $\mathrm{C} / 127 \_20$ & 5.569 & 4.884 & 6.440 & 5.798 & 2.403 & 2.069 & 2.819 & 2.470 & 1.314 & 1.157 & 1.583 & 1.344 \\
\hline C/127_18 & 4.790 & 4.237 & 5.620 & 4.950 & 2.070 & 1.813 & 2.468 & 2.118 & 1.056 & 1.021 & 1.389 & 1.155 \\
\hline C/200_20 & 9.396 & 8.282 & 11.360 & 10.048 & 4.100 & 3.684 & 5.050 & 4.391 & 2.258 & 2.017 & 2.817 & 2.414 \\
\hline $\mathrm{C} / 170 \_18$ & 6.746 & 6.022 & 8.144 & 7.117 & 2.910 & 2.585 & 3.581 & 3.077 & 1.633 & 1.452 & 2.013 & 1.695 \\
\hline C/140_16 & 4.423 & 3.957 & 5.361 & 4.618 & 1.899 & 1.723 & 2.368 & 1.994 & 1.074 & 0.967 & 1.331 & 1.093 \\
\hline $\mathrm{C} / 127 \_15$ & 3.552 & 3.147 & 4.282 & 3.656 & 1.600 & 1.413 & 1.909 & 1.584 & 0.881 & 0.760 & 1.059 & 0.860 \\
\hline $\mathrm{C} / 155 \_15$ & 4.478 & 4.529 & 5.719 & 4.800 & 1.994 & 1.995 & 2.535 & 2.081 & 1.077 & 0.961 & 1.358 & 1.113 \\
\hline $\mathrm{C} / 185 \_15$ & 5.478 & 4.976 & 6.880 & 5.810 & 2.407 & 2.239 & 3.069 & 2.545 & 1.372 & 1.243 & 1.720 & 1.404 \\
\hline $\mathrm{C} / 200 \_15$ & 5.925 & 5.406 & 7.482 & 6.288 & 2.637 & 2.412 & 3.329 & 2.755 & 1.477 & 1.331 & 1.862 & 1.521 \\
\hline
\end{tabular}


Table 5. Summary of comparisons between FE results and design calculations

\begin{tabular}{|c|c|c|c|c|c|c|c|}
\hline \multirow{2}{*}{$\begin{array}{l}\text { Section } \\
\text { type }\end{array}$} & \multirow{2}{*}{$\begin{array}{l}\text { No. of 2-span } \\
\text { FE models }\end{array}$} & \multicolumn{2}{|c|}{$\mathrm{q}_{1, \mathrm{~g} / \mathrm{q}_{\mathrm{FE}, \mathrm{g}}}$} & \multicolumn{2}{|c|}{$\mathrm{q}_{2, \mathrm{~g}} / \mathrm{q}_{\mathrm{FE}, \mathrm{g}}$} & \multicolumn{2}{|c|}{$\mathrm{q}_{3, \mathrm{~g} /} / \mathrm{q}_{\mathrm{FE}, \mathrm{g}}$} \\
\hline & & MEAN & $\mathrm{COV}$ & MEAN & $\mathrm{COV}$ & MEAN & $\mathrm{COV}$ \\
\hline Zeta I & 27 & 0.758 & 0.059 & 1.032 & 0.057 & 0.960 & 0.043 \\
\hline Zeta II & 33 & 0.801 & 0.069 & 1.090 & 0.064 & 0.987 & 0.036 \\
\hline Zed & 18 & 0.838 & 0.046 & 1.152 & 0.046 & 1.022 & 0.050 \\
\hline $\mathrm{C}$ & 27 & 0.904 & 0.040 & 1.232 & 0.031 & 1.032 & 0.025 \\
\hline All & 105 & 0.823 & 0.086 & 1.122 & 0.084 & 1.000 & 0.049 \\
\hline
\end{tabular}

